\title{
Common Blood Flow Changes across Visual Tasks: II. Decreases in Cerebral Cortex
}

\section{Citation}

Shulman, Gordon L., Julie A. Fiez, Maurizio Corbetta, Randy L. Buckner, Francis M. Miezin, Marcus E. Raichle, and Steven E. Petersen. 1997. "Common Blood Flow Changes Across Visual Tasks: II. Decreases in Cerebral Cortex." Journal of Cognitive Neuroscience 9 (5) (October): 648663. doi:10.1162/jocn.1997.9.5.648.

\section{Published Version}

doi:10.1162/jocn.1997.9.5.648

\section{Permanent link}

http://nrs.harvard.edu/urn-3:HUL.InstRepos:33896770

\section{Terms of Use}

This article was downloaded from Harvard University's DASH repository, and is made available under the terms and conditions applicable to Other Posted Material, as set forth at http:// nrs.harvard.edu/urn-3:HUL.InstRepos:dash.current.terms-of-use\#LAA

\section{Share Your Story}

The Harvard community has made this article openly available.

Please share how this access benefits you. Submit a story.

\section{Accessibility}




\title{
Common Blood Flow Changes across Visual Tasks: II. Decreases in Cerebral Cortex
}

\author{
Gordon L. Shulman, Julie A. Fiez, Maurizio Corbetta, \\ Randy L. Buckner, Francis M. Miezin, Marcus E. Raichle, and \\ Steven E. Petersen \\ Washington University School of Medicine
}

\begin{abstract}
- Nine previous positron emission tomography (PET) studies of human visual information processing were reanalyzed to determine the consistency across experiments of blood flow decreases during active tasks relative to passive viewing of the same stimulus array. Areas showing consistent decreases during active tasks included posterior cingulate/precuneous (Brodmann area, BA 31/7), left (BAs 40 and 39/19) and right (BA 40) inferior parietal cortex, left dorsolateral frontal cortex (BA 8), left lateral inferior frontal cortex (BA 10/47), left inferior temporal gyrus (BA 20), a strip of medial frontal regions running along a dorsal-ventral axis (BAs 8,9,10, and 32), and the right amygdala.

Experiments involving language-related processes tended to show larger decreases than nonlanguage experiments. This trend mainly reflected blood flow increases at certain areas in the passive conditions of the language experiments (relative to a fixation control in which no task stimulus was present) and slight blood flow decreases in the passive conditions of the nonlanguage experiments. When the active tasks were referenced to the fixation condition, the overall size of blood flow decreases in language and nonlanguage tasks were the same,
\end{abstract}

\section{INTRODUCTION}

Task-dependent increases in cerebral blood flow are often demonstrated by comparing an active task to a passive condition in which the same stimulus is presented but the subject is not given a task. Surprisingly, large blood flow decreases are also observed in active minus passive images (Friston, Frith, Liddle, $\&$ Frackowiak, 1991; Haxby et al., 1994). Blood flow increases in a cortical region are usually assumed to reflect increases in neural activity at that region because of the importance of local, interneuronal processing within cortex. Correspondingly, blood flow decreases in a cortical area might reflect decreases in neuronal activity because the cells in that area are either more inhibited or less driven by afferent projections.

Explanations of active minus passive decreases in neural activity can be grouped into two general categories. but differences were found across cortical areas. Decreases were more pronounced in the posterior cingulate/precuneous (BAs 31/7) and right inferior parietal cortex (BA 40) during language-related tasks and more pronounced in left inferior frontal cortex (BA 10/47) during nonlanguage tasks.

Blood flow decreases did not generally show significant differences across the active task states within an experiment, but a verb-generation task produced larger decreases than a read task in right and left inferior parietal lobe (BA 40) and the posterior cingulate/precuneous (BA 31/7), while the read task produced larger decreases in left lateral inferior frontal cortex (BA 10/47). These effects mirrored those found between experiments in the language-nonlanguage comparison.

Consistent active minus passive decreases may reflect decreased activity caused by active task processes that generalize over tasks or increased activity caused by passive task processes that are suspended during the active tasks. Increased activity during the passive condition might reflect ongoing processes, such as unconstrained verbally mediated thoughts and monitoring of the external environment, body, and emotional state.

First, decreases may reflect processes related to the active task. Active tasks may produce decreases in neural activity within an area that is tonically active. For example, the tonic activity of neurons in the substantia nigra pars reticulata is decreased during a saccade (Hikosaka \& Wurtz, 1983). Similarly, an active task may inhibit an area that would normally respond in the task environment. Performance of a difficult visual discrimination in the presence of distracting auditory transients, for example, might produce inhibition of ongoing activity in auditory areas (Haxby et al., 1994). Friston et al. (1991) suggested that tasks involving the intrinsic generation of words increase activity in dorsolateral prefrontal cortex, which then inhibits superior temporal regions involved in extrinsic word generation.

In these examples, different tasks decreased neural activity in different areas (e.g., the substantia nigra in a saccade task and auditory cortex in a visual discrimination task). It is also possible, however, that all active tasks 
inhibit the same areas. The aroused state typical of any active task, for example, may require the inhibition of particular areas.

Second, decreased blood flow during the active tasks may reflect the absence of processes that normally occur during the passive condition. Ongoing processes in the passive condition that are suspended during the active task, for example, might reflect monitoring of the external environment or unconstrained thought processes. This hypothesis implies that the passive condition engages a set of processes that are different from those engaged by most active tasks.

The interpretation of blood flow decreases during active tasks is partly constrained by their consistency across tasks. If each active task inhibits different areas (as in the saccade and visual discrimination examples), consistent decreases should not be found. If each active task inhibits the same area (as in the arousal example), similar decreases should be found across tasks. If decreases represent ongoing processes in the passive state, decreases should also generalize across active tasks, since the passive condition is similar across tasks.

This paper presents a reanalysis of nine PET studies of visual processing in order to determine the generality of blood flow decreases across tasks. Each study involved a set of active conditions, in which subjects performed a variety of tasks upon a stimulus, and a passive condition, in which the same stimulus was presented, but the subject was not given a task. Decreases that generalized across tasks were examined by averaging active minus passive blood flow changes across all studies.

\section{RESULTS}

\section{Replication analyses}

The reliability of the blood flow decreases in an overall megaimage that averaged active minus passive scan pairs across all experiments was determined (see previous paper, Shulman, Corbetta, Buckner, Fiez, et al., 1997, for details of method). Blood flow decreases were identified in a megaimage based on a hypothesis-generating (generate) group of scan pairs and tested for reliability, via a one-sample $t$ test, in a nonoverlapping hypothesis-testing (test) group of scan pairs. Nineteen foci from the generate megaimage met the two selection criteria: (1) the magnitude of the active minus passive decreases was greater than 15 PET counts ${ }^{1}$ and (2) the sample size exceeded 50 subjects (Table 1). Sixteen of these foci replicated in the test group at a 0.05 level, Bonferroni corrected for the number of comparisons $(p<0.0026)$. Of these 16 foci, 14 corresponding foci were found in the generate plus test megaimage that combined the scan pairs from the generate and test groups. These foci (Figure 1) were located in the junction of the posterior cingulate and precuneous (BA 31/7), left (BAs 40 and 39/19) and right (BA 40) inferior parietal cortex, left dorsolateral frontal cortex (BA 8), an extended medial strip running dorsal-ventral in frontal cortex (BAs 8, 9, and 10 ) and continuing through inferior anterior cingulate (BA 32), left inferior frontal cortex (BA10/47), the left inferior temporal gyrus (BA 20), and the right amygdala.

\section{Analyses of Additional Blood Flow Changes}

The generate plus test megaimage was analyzed for all decreases whose magnitude exceeded 10 PET counts. Foci not previously found from the replication analysis generally had smaller $z$-scores and magnitudes (Table 2). Some foci had coordinates homologous to a region noted in Table 1 in the other hemisphere [e.g., right anterior parietal cortex (BA 40), left amygdala, right inferior temporal gyrus (BA 20), and right prefrontal cortex (BA 10)]. Of all foci less than 10 PET counts, only one, in BA 24/31, had a $z$-score that exceeded 3.08. While some foci in Table 2 may reflect "real" decreases, their reliability is uncertain since they were not tested for replicability. Subsequent analyses are limited to the 14 foci from the replication analysis.

\section{Between-Experiments Analyses}

Several analyses examined the consistency across experiments of the decreases at the 14 foci.

\section{Between-Experiments ANOVAs}

Figures 2 through 5 show the magnitude for each of the I4 foci across the nine experiments, with parietal lobe foci in Figure 2, frontal lobe foci in Figures 3 and 4, and temporal lobe foci in Figure 5. Decreases were present at most foci for most experiments, but significant variation across experiments was noted for 8 foci $(p$ values for a 1 factor between-subjects ANOVA with Experiment as the factor are shown in Figures 2 through 5). Subsequent analyses partly explore the cause of this variation.

\section{Single-Process Analyses}

The consistency of the 14 foci across broadly defined processes (e.g., language-related or nonlanguage processes) was examined. Language, nonlanguage, motor (e.g., motor responses occurred in the active but not passive condition), and matched-motor (e.g., motor responses in the active and passive conditions were identical) megaimages were constructed by combining the appropriate experiments (Tables 3 and 4). Decreases were present at most foci for all four megaimages, but there were clear exceptions. The blood flow decrease at the right inferior parietal focus (BA 40) only occurred very weakly in the nonlanguage and matched-motor megaimages. Weak decreases were also seen in the non- 
Table 1. The left columns show the coordinates of foci from the generate megaimage that replicated and the magnitudes and $p$ values for the replication in the test group. The right columns show the coordinates, sample sizes, magnitudes, and $z$-scores of foci from the generate plus test megaimage that were nearest those generate foci that replicated with a Bonferroni correction. In some cases, a separate generate plus test focus could not be found for a focus from the generate megaimage (e.g., $\mathrm{L}$ 40). The first column shows the number of each focus displayed in Figure 1. The superscript a refers to test statistics collected with a $50 \%$ sampling criterion.

\begin{tabular}{|c|c|c|c|c|c|c|c|c|c|c|c|c|}
\hline \multirow[b]{2}{*}{ Area } & \multirow{2}{*}{$\begin{array}{c}\text { Focus } \\
\text { No. }\end{array}$} & \multicolumn{3}{|c|}{ Generate coordinate } & \multirow{2}{*}{$\frac{\text { Test }}{\text { Mag. }}$} & \multirow[b]{2}{*}{$p$ value } & \multicolumn{5}{|c|}{ Generate plus Test } & \multirow[b]{2}{*}{$z$-score } \\
\hline & & $X$ & $\boldsymbol{Y}$ & $Z$ & & & $\boldsymbol{X}$ & $Y$ & $Z$ & $N$ & Mag. & \\
\hline \multicolumn{13}{|l|}{ Parietal Lobe } \\
\hline 31 & & 1 & -35 & 34 & -10 & $<0.0005$ & & & & & & \\
\hline $31 / 7$ & 1 & -7 & -53 & 34 & -20 & $<0.0001$ & -5 & -49 & 40 & 130 & -21 & -6.7 \\
\hline $\mathrm{L} 40$ & 2 & -57 & -35 & 40 & -16 & $<0.0001$ & -53 & -39 & 42 & 128 & -17 & -6.7 \\
\hline L 40 & & -49 & -53 & 36 & -17 & $<0.0001$ & & & & & & \\
\hline L $39 / 19$ & 3 & -43 & -69 & 36 & -12 & $<0.001$ & -45 & -67 & 36 & 131 & -20 & -7.1 \\
\hline R 40 & 4 & 49 & -55 & 40 & -11 & $<0.001$ & 45 & -57 & 34 & 131 & -16 & -5.5 \\
\hline \multicolumn{13}{|l|}{ Frontal Lobe } \\
\hline L lateral 8 & 5 & -29 & 29 & 40 & -13 & $<0.0001$ & -27 & 27 & 40 & 131 & -17 & -6.4 \\
\hline L $8 / 9$ & 6 & -9 & 43 & 42 & -10 & $<0.002$ & -11 & 41 & 42 & 131 & -17 & -6.8 \\
\hline R 8/9 & 7 & 11 & 43 & 44 & -10 & $<0.001$ & 5 & 49 & 36 & 132 & -17 & -6.2 \\
\hline L 9 & 8 & -17 & 63 & 18 & -11 & $<0.002$ & -15 & 55 & 26 & 131 & -17 & -6.5 \\
\hline L 10 & 9 & & & & & & -19 & 57 & 8 & 125 & -20 & -6.7 \\
\hline 10 (superior) & & -1 & 55 & 10 & -21 & $<0.0001$ & & & & & & \\
\hline 10 & 10 & -1 & 49 & -6 & -26 & $<0.0001$ & -1 & 47 & -4 & 95 & -29 & -7.7 \\
\hline L $10 / 47$ & 11 & -35 & 47 & -6 & -14 & $<0.0005$ & -33 & 45 & -6 & 87 & -16 & -4.7 \\
\hline 32 & 12 & -3 & 19 & -14 & $-12^{\mathrm{a}}$ & $<0.0005$ & 3 & 31 & -10 & 73 & -17 & -4.6 \\
\hline \multicolumn{13}{|l|}{ Temporal Lobe } \\
\hline L 20 & 13 & -47 & -23 & -16 & -14 & $<0.0005$ & -49 & -19 & -18 & 65 & -17 & -4.9 \\
\hline $\mathrm{L}$ amygdala & & -21 & 1 & -20 & $-10^{\mathrm{a}}$ & $<0.01$ & & & & & & \\
\hline $\mathrm{R}$ amygdala & 14 & 17 & -7 & -18 & $-13^{a}$ & $<0.001$ & 21 & -9 & -18 & 55 & -20 & -4.6 \\
\hline
\end{tabular}

language megaimage for the right amygdala and inferior anterior cingulate (BA 32) and in the matched-motor megaimage for left inferior frontal cortex (BA 10/47). Blood flow decreases at all foci were generally larger for experiments involving a language or motor factor. Because of the confounding of variables across experiments (particularly language and motor variables), however, between-experiments comparisons must be interpreted cautiously. Post-hoc contrasts are also only warranted for foci showing differences in the overall ANOVA.

In summary, decreases at most foci were consistent across experiments and were not limited to active tasks involving language, nonlanguage, or simple motor execution, although they may have been modulated by these processes. The strong between-experiments variation for right inferior parietal cortex (BA 40), however, may have reflected a language/motor requirement.

\section{Within-Experiment Analyses}

Decreases at the megaimage foci did not generally differ across the conditions within an experiment, but significant differences were found between the verb-generation and read tasks of the Language and Practice Language experiments. Several parietal areas [left $(t(19)=3.11, p<0.01)$ and right $(t(19)=3.70, p<$ $0.005) \mathrm{BA} 40$ and $\mathrm{BA} 31 / 7(t(19)=2.46, p<0.025)]$ showed larger decreases in the verb-generation than read tasks, while two left frontal areas [BA10/47 $(t(19)=$ $3.77, p<0.005)$ and BA $9(t(19)=2.41, p=0.026)$ ] 


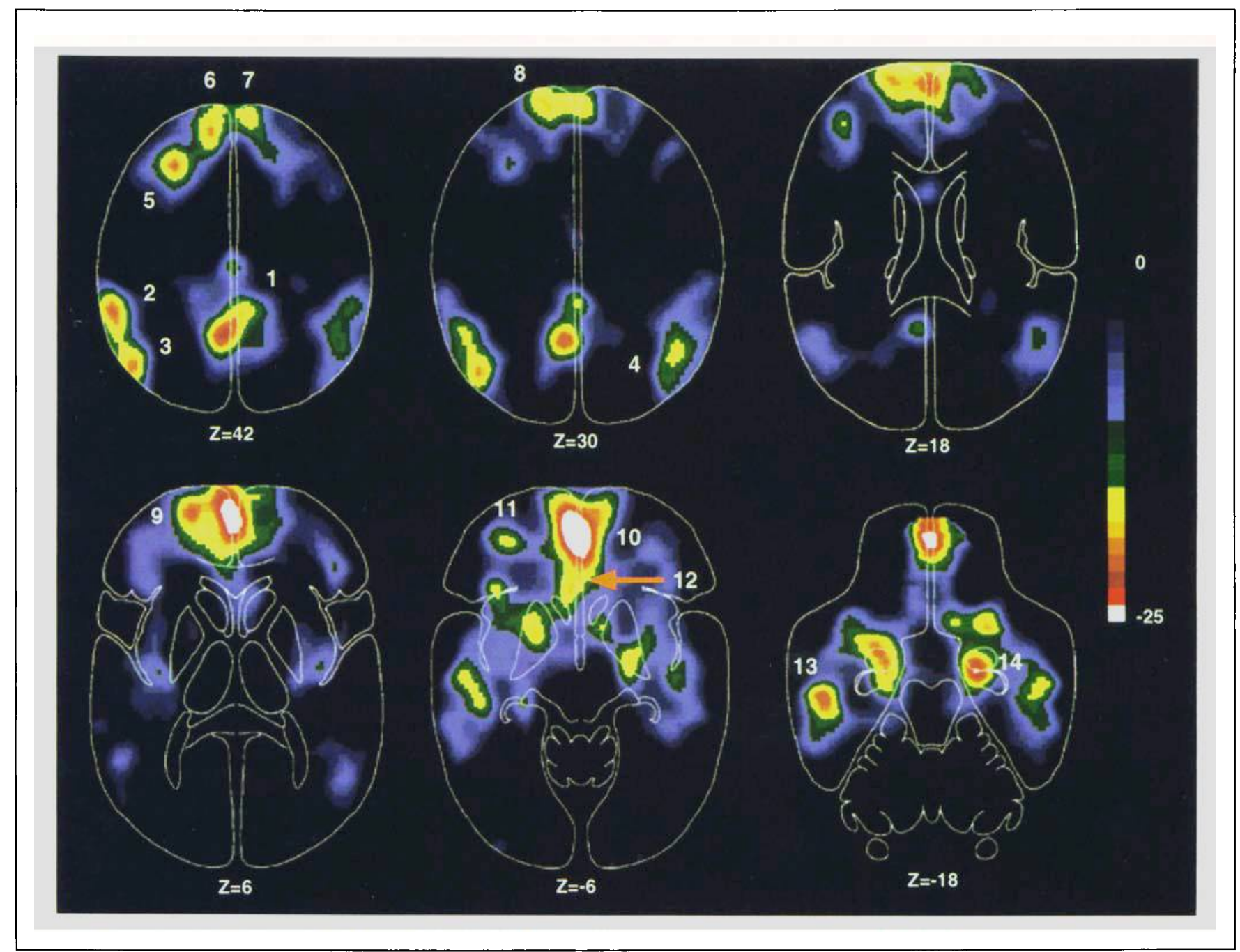

Figure 1. Blood flow decreases in an overall megaimage that averaged the active minus passive scan pairs from all experiments. Numbers indicate the 14 foci that passed the replication procedure and produced a separate focus in the megaimage.

showed larger decreases in the read than verb-generation task.

These within-experiment differences were consistent with the between-experiments comparisons. For example, right inferior parietal cortex (BA 40), which showed larger decreases in the language-related experiments, also showed larger decreases in the more demanding linguistic task (i.e., verb generation). The correlation over the 14 foci between the verb-generation minus read and the language minus nonlanguage magnitudes (from Table 4) was $0.80(p<0.0005$; Figure 6). This congruence of the within- and between-experiments analyses suggests that at least some of the significant differences between the language and nonlanguage megaimages were not due to correlated motor factors or stimulus eccentricity, which were both equated in the verb-generation and read tasks.

The above comparison of the verb-generation and read tasks was conducted for those conditions in which subjects viewed new word lists. Raichle et al. (1994) showed that practicing the verb-generation task with the same word list changed the blood flow pattern produced by that task, relative to the read task. A verb-generation minus read subtraction, for example, yielded less activity after practice in left prefrontal cortex. Practice also made the verb generation considerably easier, reflected in a sharp reduction in reaction time (Raichle et al., 1994). An analysis of the data from the Raichle et al. experiment (e.g., Practice Language) yielded an interaction of Task (verb generation, read) and Practice (naive, practiced, novel) at the left inferior frontal (BA 10/47) megaimage focus $(F(2,14)=3.87, p<0.05)$. While decreases were greater for the read than verb-generation task during the novel and naive conditions, equivalent decreases were found in the practiced conditions. This result is consistent with the earlier report. No significant interactions, however, were found at the parietal foci that showed larger decreases during the verb-generation 
Table 2. All blood flow decreases exceeding a magnitude criterion of -10 PET counts in the generate plus test overall megaimage that were not listed in the right panel of Table 1 .

\begin{tabular}{lrrrrrr}
\hline & $X$ & $Y$ & $Z$ & $N$ & Mag. & Z-score \\
\hline Parietal Lobe & & & & & & \\
7 & 1 & -43 & 56 & 64 & -12 & -3.7 \\
R 40 & 51 & -39 & 42 & 128 & -11 & -4.0 \\
Frontal Lobe & & & & & & \\
R 8 & 15 & 29 & 48 & 129 & -12 & -4.9 \\
L 46 & -39 & 41 & 18 & 131 & -12 & -4.7 \\
L insula & -35 & -13 & 2 & 131 & -11 & -3.8 \\
R insula & 39 & -11 & 4 & 131 & -10 & -3.7 \\
R 10 & 21 & 55 & 14 & 131 & -12 & -3.9 \\
L 47 & -35 & 13 & -12 & 75 & -12 & -4.0 \\
R 47 & 27 & 15 & -14 & 60 & -15 & -3.3 \\
Temporal Lobe & & & & & & \\
R 20 & 49 & -15 & -18 & 61 & -14 & -3.7 \\
R 20/21 & 51 & -33 & -12 & 113 & -11 & -4.0 \\
R 22 & 47 & -55 & 16 & 132 & -11 & -4.4 \\
L 35/36 & -25 & -27 & -10 & 115 & -10 & -3.5 \\
L amygdala & -21 & -9 & -22 & 28 & -19 & -3.6 \\
\hline
\end{tabular}

than read task. Decreases at these foci were not affected by changes in the difficulty of the verb-generation task.

\section{Passive Minus Fixation Analyses}

\section{Effects of Motor Responses on Blood Flow Decreases}

Motor responses were made in some passive conditions, but not others, while responses were never made in the fixation condition. Passive minus fixation magnitudes for conditions that did (unmatched-motor) or did not (matched-motor) involve a response were measured at the foci from the active minus passive megaimage in order to determine whether simple motor responses could produce decreases at those foci. Magnitudes and $z$-scores were similar in the matched- and unmatchedmotor megaimages, indicating that motor responses were not sufficient to produce decreases.

\section{Effects of Stimuli on Blood Flow Decreases}

Since the stimulus in most fixation conditions was simply a small fixation cross, an analysis of the passive minus fixation data at the active minus passive foci also indicated whether a stimulus could produce blood flow changes at these foci. Passive minus fixation magnitudes in the language experiments ${ }^{2}$ (which involved letter strings) were moderately positive at several left hemisphere foci (Table 5), while magnitudes in the nonlanguage experiments tended to be slightly negative (i.e., blood flow was greater in the fixation than in the passive condition).

Inspection of the nonlanguage megaimage for local changes (with magnitudes exceeding 15 PET counts) near the active minus passive foci yielded no increases or decreases. The language megaimage, however, yielded increases in left hemisphere regions near those in Table 5 (left BAs 20,9,8/9,10/47, and 40) and sizable decreases in the posterior cingulate and precuneous (coordinate $=$ 9, $-49,44 ;$ magnitude $=-32, z=-4.2 ;$ coordinate $=-1$, $-63,34 ;$ magnitude $=-36, z=-4.9 ;$ coordinate $=5,-79$, 44; magnitude $=-30, z=-4.4$ ).

These results indicate that the passive baseline was shifted (relative to fixation) in several areas in the language and nonlanguage experiments. The increased blood flow at certain foci caused by the passive presence of a letter string made the active minus passive decreases at those foci even larger relative to the decreases that would have been obtained if the fixation point condition were used as a control. Conversely, the slightly decreased blood flow in nonlanguage passive minus fixation scan pairs made the active minus passive decreases smaller.

The passive presence of a letter string produced a pattern of changes at the active minus passive foci that was similar to the pattern of changes produced at these foci by the verb-generation task relative to the read task. The correlation across foci between the passive minus fixation magnitudes in the language megaimage and the verb-generation minus read magnitudes was $0.63(p<$ 0.02 ; Figure 6 ). Therefore, differences between the verbgeneration and read tasks in the within-experiment analyses were not solely due to the greater difficulty of the verb-generation task.

\section{Active Minus Fixation Analyses}

An active minus fixation megaimage was constructed in order to explore the implications of the shifted baselines in the language and nonlanguage experiments. The magnitudes in this megaimage at the 14 active minus passive foci were well approximated by adding the active minus passive and passive minus fixation magnitudes. Across foci, the average active minus fixation decrease was -I6 PET counts for both the language and nonlanguage experiments. This result confirms that the larger active minus passive decreases in the language than nonlanguage studies (Table 4) were caused by shifts in the corresponding passive conditions.

Active minus fixation decreases were significantly greater for the language than nonlanguage experiments in the right inferior parietal cortex (BA 40) $(t(74)=2.59$, $p<0.02$ ) and precuneous/posterior cingulate (BA 31/7) $(t(74)=2.67, p<0.01)$ and significantly greater for the 
Figure 2. Each graph shows the active minus passive decreases (in PET counts) across experiments at a single parietal focus from the overall megaimage. The $p$ value for a 1-factor ANOVA with Experiments as the factor is shown for each focus. The four experiments involving languagerelated processes are shown on the right of each graph, while the five nonlanguage experiments are on the left. Experiments in bold type involved a motor response in the active conditions but no response in the passive conditions.

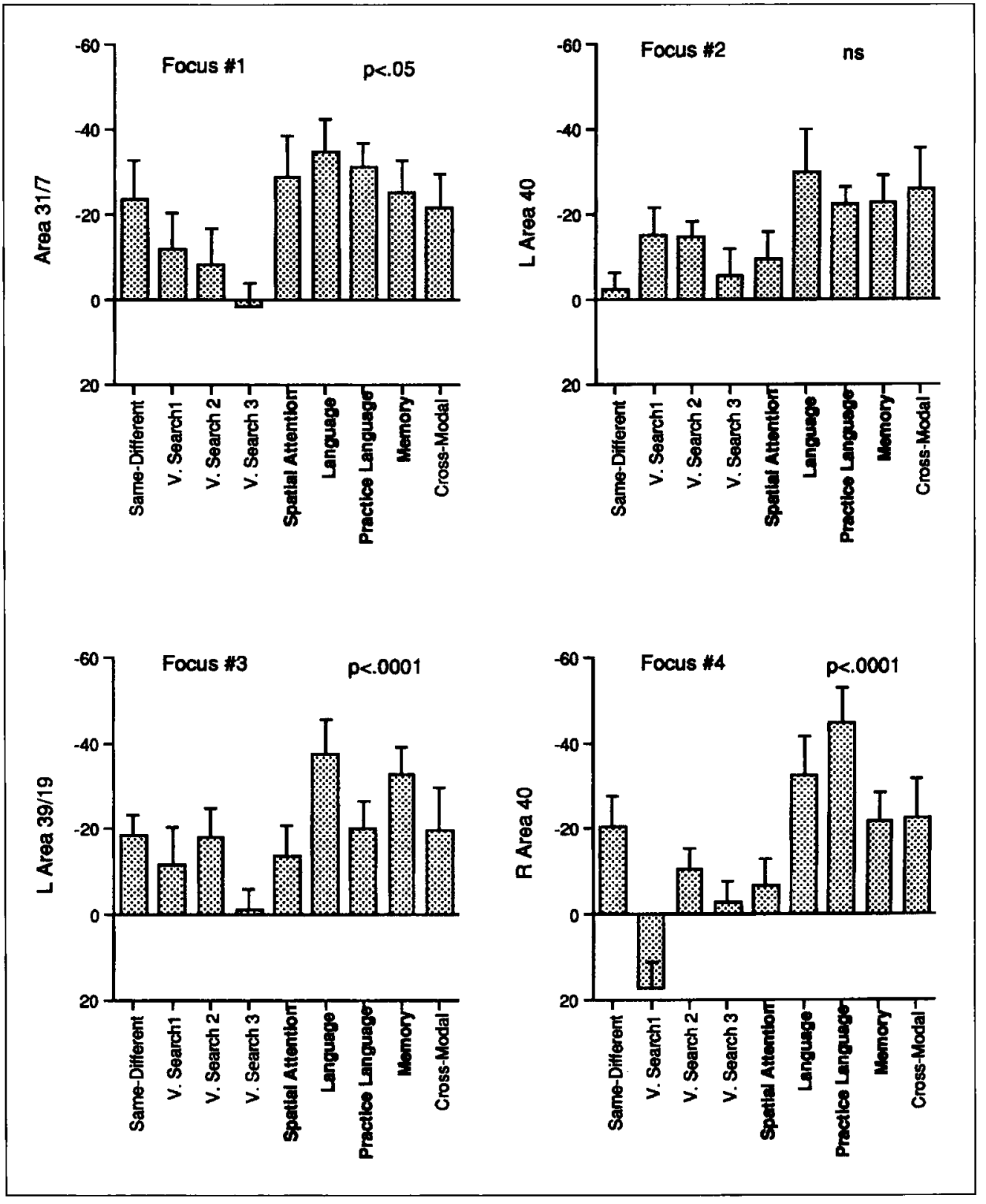

nonlanguage than language experiments in left inferior frontal cortex (BA 10/47) $(t(42)=2.26, p<0.05)$. These differences (Figure 7 ) parallel the differences noted earlier between the verb-generation and read tasks. The correlation between the verb-generation minus read (active minus passive) magnitudes and the language minus nonlanguage (active minus fixation) magnitudes was $0.78(p<0.001)$. If the verb-generation minus read magnitudes are taken from only the Practice Language experiment, which did not contribute any active minus fixation data, the correlation was $0.67(p<0.01)$.

While language-nonlanguage differences in parietal areas were also found in the active minus passive analysis, the left inferior frontal difference was not previously seen. The active minus passive decrease for left inferior frontal cortex (BA 10/47) was similar for the language and nonlanguage experiments (Table 4). Since the passive presence of a letter string produced increases in this area, however, the net active minus fixation decrease was larger for the nonlanguage than language studies.

\section{DISCUSSION}

Following a summary of the results, this section discusses (1) the effects of several correlated variables on decreases in order to isolate the critical variables, (2) the methodological implications of the results, (3) a nonfunctional explanation of decreases involving the redistribution of the blood supply, (4) a functional explanation related to active task processes, (5) a functional 
Figure 3. Frontal lobe decreases in the overall megaimage. See Figure 2 caption for details.

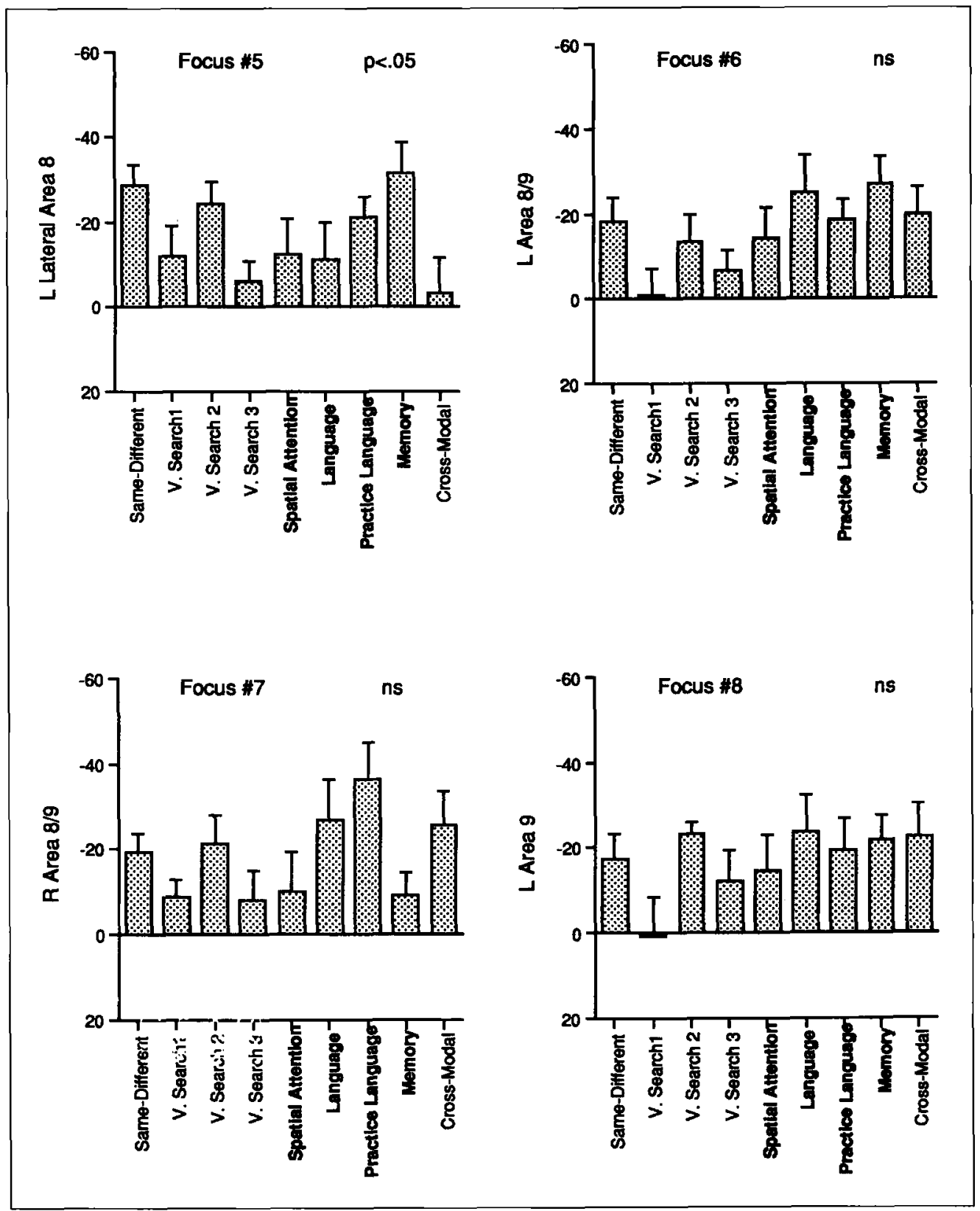

explanation related to ongoing processes in the passive state, and (6) hypotheses concerning why these passive processes may be suspended during active tasks.

\section{Results Summary}

1. A set of 14 foci in frontal, parietal, and temporal lobes, as well as the amygdala, showed highly reliable active minus passive decreases that were present in most or many experiments. A similar consistency in cerebral cortex was not present for active minus passive increases, aside from the expected motor or sensory effects (Shulman, Corbetta, Buckner, Fiez, et al., 1997).

2. Blood flow decreases did not generally show significant differences across active tasks within an experi- ment, but the verb-generation task produced larger decreases than the read task in parietal areas (BAs 40 and $31 / 7$ ) and smaller decreases in left frontal areas (BAs 9 and $10 / 47)$.

3. Language tasks produced larger decreases in parietal areas (BAs 40 and 31/7) when tasks were referenced to either a fixation point or passive baseline. Nonlanguage tasks produced larger decreases in a left inferior frontal region (BA 10/47) when tasks were referenced to a fixation baseline. This reciprocal pattern mirrored that shown for the verb-generation and read tasks. Language minus nonlanguage magnitudes were highly correlated across active minus passive foci with verb-generation minus read magnitudes.

4. Production of a simple motor response was not 
Figure 4. Frontal lobe decreases in the overall megaimage. See Figure 2 caption for details.

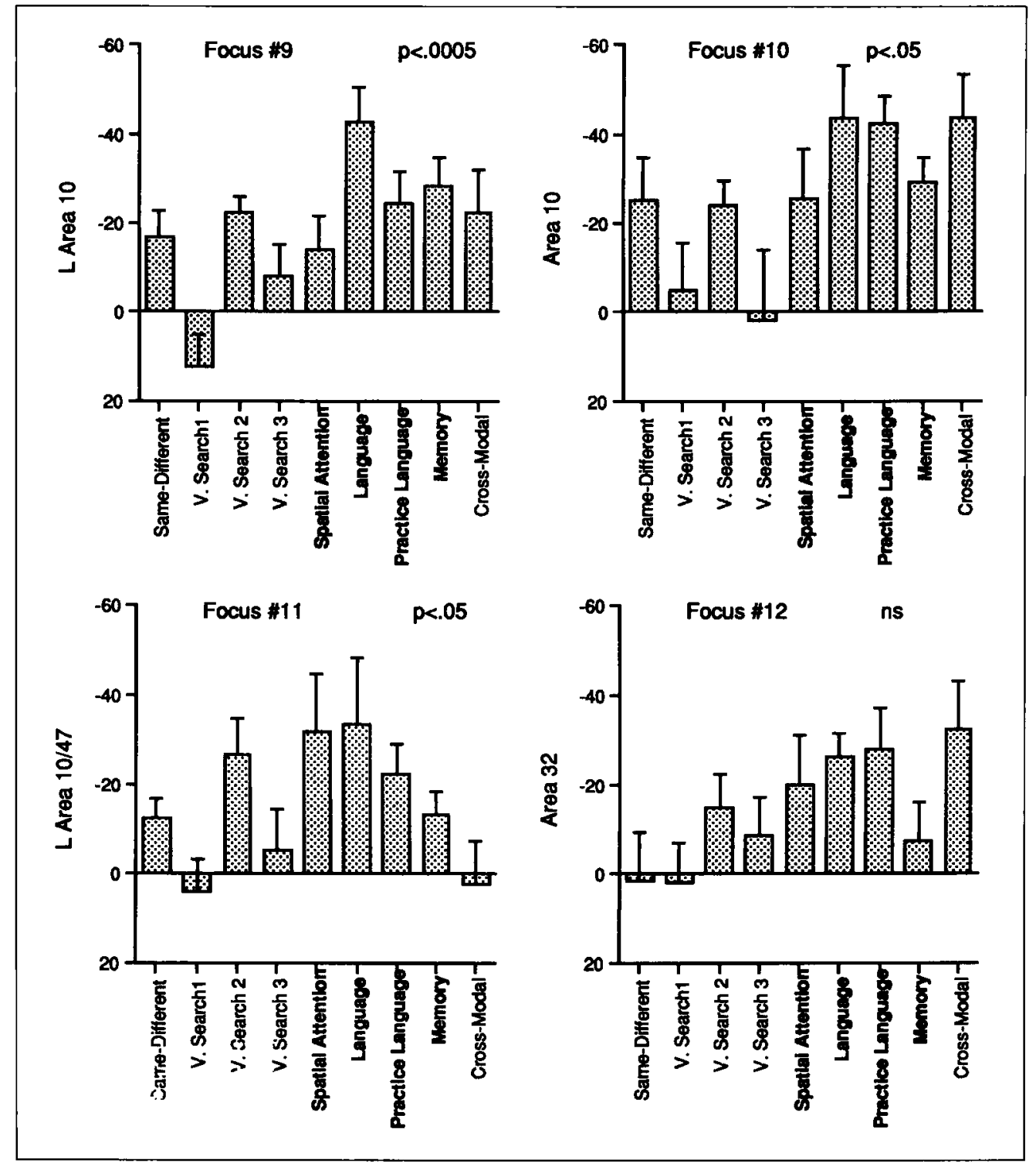

sufficient to produce decreases at the foci from the active minus passive megaimage. The presence of a letter string, however, increased blood flow at several left hemisphere foci (BAs 20,9,8/9, 10/47, and 40), produced sizable decreases in the precuneous, and showed a pattern of changes at the active minus passive foci similar to that produced by the verb-generation task relative to the read task.

\section{Variables Affecting Blood FIow Decreases}

Significant between-experiments differences were found at a number of megaimage foci but were difficult to interpret because the main variables distinguishing the experiments were highly correlated: motor response in the active but not passive condition, language/task difficulty (i.e., the language tasks may have been more difficult than the nonlanguage tasks), and stimulus eccentricity.

\section{Language/Task Difficulty versus Motor}

Two results suggested that the language/task difficulty variable rather than the motor variable contributed to the between-experiments differences. First, betweenexperiments language/nonlanguage differences were paralleled by within-experiment differences in the verbgeneration and read tasks, in which the motor response was held constant. Second, the passive minus fixation data indicated that simple motor processes were not sufficient to produce decreases. ${ }^{3}$

\section{Language versus Task Difficulty}

Task difficulty cannot explain the language/nonlanguage differences at both the parietal and left frontal foci because they were opposite in sign (i.e., larger parietal decreases in the language experiments and larger frontal decreases in the nonlanguage experiments). Differences 
Figure 5. Temporal lobe decreases in the overall megaimage. See Figure 2 caption for details.

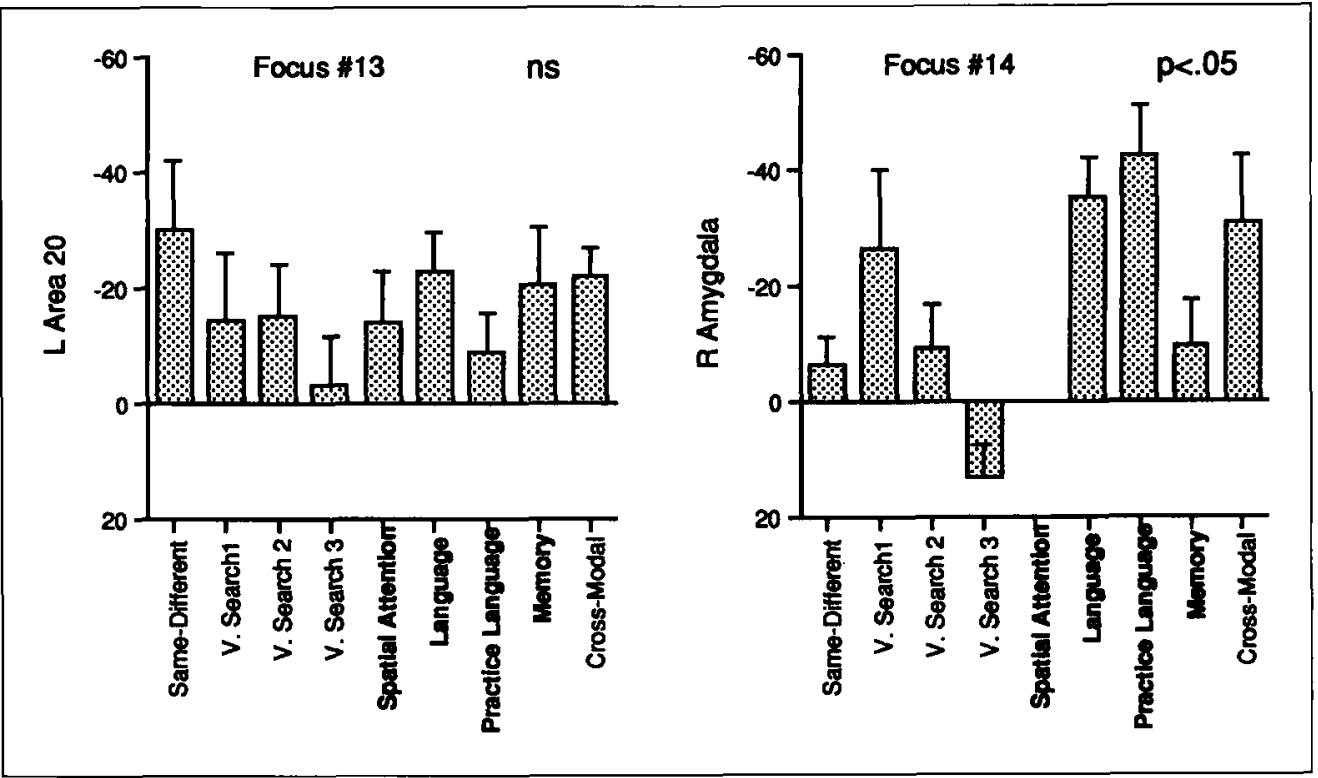

Table 3. Sample sizes, magnitudes, and $z$-scores of decreases at the overall megaimage foci for those experiments in which the active task involved a motor response but no response was made in the passive (unmatched-motor) task and for those experiments in which the motor requirements of the active and passive tasks were the same (matched-motor). The last column shows the two-tailed $p$ value for an unpaired $t$ test comparing the magnitudes of the decreases in the unmatchedand matched-motor experiments. ns refers to $p>0.05$.

\begin{tabular}{|c|c|c|c|c|c|c|c|}
\hline \multirow[b]{2}{*}{ Area } & \multicolumn{3}{|c|}{ Unmatched-motor } & \multicolumn{3}{|c|}{ Matched-motor } & \multirow[b]{2}{*}{$p$ value } \\
\hline & $N$ & Mag. & $\mathrm{z}$-score & $N$ & Mag. & $\mathrm{z}$-score & \\
\hline \multicolumn{8}{|l|}{ Parietal Lobe } \\
\hline $31 / 7$ & 67 & -29 & -6.1 & 63 & -12 & -3.1 & $<0.005$ \\
\hline I. 40 & 65 & -21 & -5.3 & 63 & -13 & -4.0 & ns \\
\hline L $39 / 19$ & 67 & -26 & -6.1 & 64 & -13 & -3.8 & $<0.01$ \\
\hline R 40 & 67 & -24 & -5.4 & 64 & -7 & -2.1 & $<0.005$ \\
\hline \multicolumn{8}{|l|}{ Frontal Lobe } \\
\hline L lateral 8 & 66 & -20 & -4.7 & 65 & -14 & -4.4 & ns \\
\hline L. $8 / 9$ & 66 & -22 & -5.5 & 65 & -12 & -4.0 & $<0.05$ \\
\hline R $8 / 9$ & 67 & -18 & -4.1 & 65 & -16 & -4.9 & ns \\
\hline L 9 & 67 & -20 & -4.8 & 64 & -15 & -4.3 & ns \\
\hline L 10 & 65 & -27 & -6.1 & 60 & -12 & -3.2 & $<0.005$ \\
\hline 10 & 51 & -35 & -6.7 & 44 & -23 & -4.2 & ns \\
\hline L $10 / 47$ & 45 & -23 & -4.6 & 42 & -9 & -1.9 & $<0.05$ \\
\hline 32 & 37 & -19 & -3.7 & 36 & -15 & -2.8 & ns \\
\hline \multicolumn{8}{|c|}{ Temporal Lobe } \\
\hline L 20 & 31 & -17 & -3.0 & 34 & -18 & -3.8 & ns \\
\hline $\mathrm{R}$ amygdala & 26 & -24 & -3.5 & 29 & -16 & -2.9 & ns \\
\hline
\end{tabular}


Table 4. Sample sizes, magnitudes, and $z$-scores of decreases at the overall megaimage foci for those experiments in which the active task involved language or nonlanguage related processes. The last column shows the two-tailed $p$ value for an unpaired $t$ test comparing the magnitudes of the decreases for the language and nonlanguage experiments. ns refers to $p>0.05$.

\begin{tabular}{|c|c|c|c|c|c|c|c|}
\hline \multirow[b]{2}{*}{ Area } & \multicolumn{3}{|c|}{ Language } & \multicolumn{3}{|c|}{ Nonlanguage } & \multirow[b]{2}{*}{$p$ value } \\
\hline & $N$ & Mag. & $\mathrm{z}$-score & $N$ & Mag. & z-score & \\
\hline \multicolumn{8}{|l|}{ Parietal Lobe } \\
\hline $31 / 7$ & 61 & -28 & -6.1 & 69 & -14 & -3.5 & $<0.05$ \\
\hline L 40 & 59 & -25 & -5.8 & 69 & -10 & -3.5 & $<0.001$ \\
\hline L $39 / 19$ & 61 & -29 & -6.2 & 70 & -12 & -4.8 & $<0.002$ \\
\hline R 40 & 61 & -29 & -5.9 & 70 & -4 & -1.5 & $<0.0001$ \\
\hline \multicolumn{8}{|l|}{ Frontal Lobe } \\
\hline L lateral 8 & 61 & -19 & -4.4 & 70 & -16 & -4.6 & ns \\
\hline L $8 / 9$ & 61 & -24 & -6.0 & 70 & -11 & -3.6 & $<0.005$ \\
\hline R 8/9 & 62 & -22 & -5.0 & 70 & -13 & -3.7 & ns \\
\hline L 9 & 62 & -22 & -5.3 & 69 & -14 & -3.8 & ns \\
\hline L 10 & 61 & -29 & -6.3 & 64 & -10 & -3.0 & $<0.0005$ \\
\hline 10 & 54 & -39 & -7.2 & 41 & -17 & -3.4 & $<0.001$ \\
\hline L $10 / 47$ & 51 & -15 & -3.2 & 36 & -17 & -3.4 & ns \\
\hline 32 & 42 & -22 & -4.2 & 31 & -10 & -2.1 & ns \\
\hline \multicolumn{8}{|l|}{ Temporal Lobe } \\
\hline L 20 & 38 & -18 & -3.4 & 27 & -16 & -2.9 & ns \\
\hline $\mathrm{R}$ amygdala & 32 & -27 & -4.3 & 23 & -10 & -1.9 & $<0.05$ \\
\hline
\end{tabular}

between the verb-generation and read tasks at these frontal and parietal foci also varied in sign. The absence of any significant Task by Practice interactions in the Practice Language experiment at the parietal foci raises further problems for a task-difficulty explanation of the larger decreases at those foci during the verb-generation task. Larger decreases were not observed in the more difficult color-form than in the color conditions of Visual Search 1 and 2 (except for BA right 8/9 in Visual Search 2) or in the more difficult conjunction than in the feature conditions of Visual Search 3. Finally, the passive minus fixation language megaimage produced a blood flow pattern similar to that in the verb-generation versus read comparison, again raising problems for a task difficulty explanation.

\section{Language versus Eccentricity}

The language experiments involved stimulus displays that were more foveal (e.g., all letter strings were presented $1^{\circ}$ below fixation and subtended less than $5^{\circ}$ ) than the nonlanguage experiments, which involved large field (Successive Same-Different Discrimination), para- foveal (Visual Search 2, Visual Search 3, Spatial Attention), or peripheral (Visual Search 1) displays. These eccentricity differences may explain the larger active minus passive decreases in the precuneous/posterior cingulate (BA 31/7) in the language experiments, since this region also showed prominent passive minus fixation decreases in these experiments (see below).

\section{Methodological Implications}

\section{The Passive as a Control Condition}

Although many studies have included a passive control in the experimental design, there may be concerns that this condition is too underspecified to provide a reliable control. The present analysis indicates that passive conditions across a wide variety of experiments produce a consistent set of blood flow changes and can serve as one control state.

\section{Task-Specific Blood Flow Decreases}

A blood flow decrease during an active task at any focus in Tables 2 or 3 does not reflect the operation of pro- 


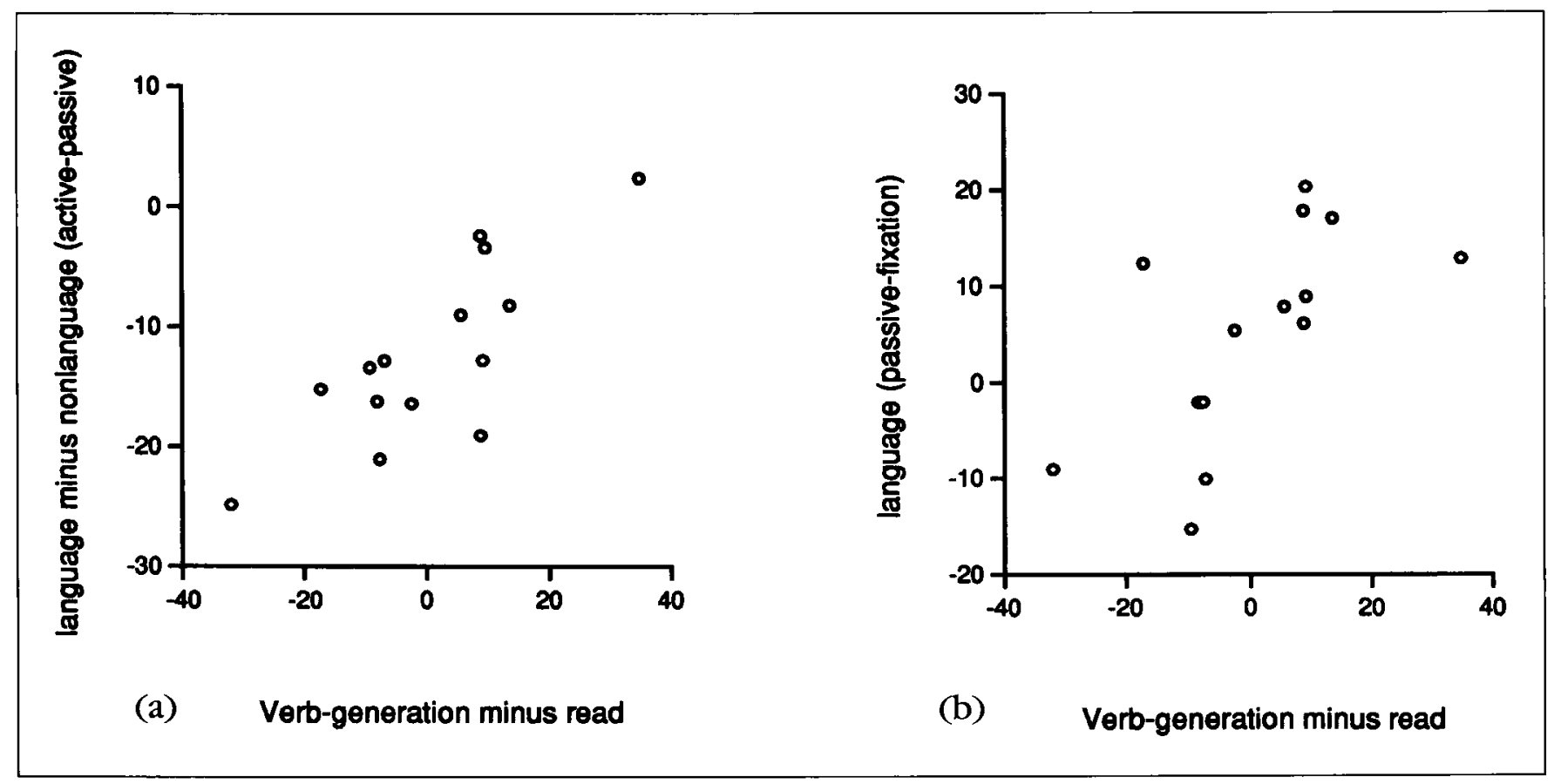

Figure 6. Scatterplots of magnitudes at the 14 active minus passive foci showing the relationship between (a) active minus passive decreases in the verb-generation minus read tasks and language minus nonlanguage experiments and (b) active minus passive decreases in the verbgeneration minus read tasks and passive minus fixation increases in the language tasks.

cesses unique to that task. Conversely, a reliable decrease at a different focus probably reflects a process relatively specific to the active task. The megaimage foci therefore provide useful information for interpreting the decreases produced by a task. The present dataset also contained task-specific decreases, although they were not discussed.

\section{Blood Flow Decreases Caused by Redistribution of the Blood Supply}

One explanation of the observed blood flow decreases concerns the redistribution of cerebral blood flow. The apparent constancy of the blood supply to the brain has led to suggestions that large blood flow increases in some areas may require decreases in other areas (e.g., see Haxby et al., 1994). Decreases, however, were often not accompanied by increases in neighboring regions (e.g., the right parietal decreases during the language tasks or the left frontal decreases during the nonlanguage tasks). Similarly, the present decreases occurred in the absence of any evidence for corresponding increases in cortex that generalized over tasks (Shulman, Corbetta, Buckner, Fiez, et al., 1997). More generally, this hypothesis fails to take into consideration the enormous reserve capacity of the brain circulation to respond to changes in the metabolic and circulatory demands of the brain. This is dramatically demonstrated during the increased metabolic demands of convulsions. In both experimental animals (Plum, Posner, \& Troy, 1968) and humans (Broderson et al., 1973; Posner, Plum, \& Van Poznak, 1969) overall brain blood flow and metabolism can increase severalfold. This not only results from the remarkable capacity of the normal brain vasculature to reduce its resistence and, hence, increase flow (Reivich, 1964) but also the capacity of the systemic circulation to support a large change in the circulatory demands of the brain by increasing cardiac output, manyfold if necessary, and increase peripheral resistence (Plum, 1968; Posner, 1969). The changes in brain blood flow during cognitive activation experiments are usually in the range of $10 \%$ or less, hardly a serious physiologic challenge to the normal brain vasculature.

\section{Blood Flow Decreases Caused by Active Task Processes}

Active minus passive decreases may reflect decreased activity related to active task processes or suspension of activity related to ongoing processes in the passive condition. If the present decreases reflected active task processes, these processes are not task-specific. This would contrast with the result of the preceding paper that active tasks do not produce common cortical increases. Although it seems unlikely that a single inhibitory process would encompass such a divergent set of cortical areas, subsets of these areas might reflect different processes. 
Table 5. Passive minus fixation data. Sample sizes, magnitudes, and $z$-scores for passive minus fixation changes at coordinates for the active minus passive megaimage foci. The left panel shows data from experiments involving linguistic stimuli (e.g., letter strings), while the right panel shows data from experiments involving nonlinguistic stimuli. The last column shows the two-tailed $p$ value for an unpaired $t$ test comparing the magnitudes of the passive minus fixation changes for the language and nonlanguage experiments.

\begin{tabular}{|c|c|c|c|c|c|c|c|}
\hline \multirow[b]{2}{*}{ Area } & \multicolumn{3}{|c|}{ Language } & \multicolumn{3}{|c|}{ Nonlanguage } & \multirow[b]{2}{*}{ p value } \\
\hline & $N$ & Mag. & z-score & $N$ & Mag. & z-score & \\
\hline \multicolumn{8}{|l|}{ Parietal Lobe } \\
\hline $31 / 7$ & 34 & -15 & -2.0 & 44 & -6 & -0.9 & ns \\
\hline L 40 & 32 & 12 & 1.7 & 44 & -4 & -0.9 & $<0.05$ \\
\hline L $39 / 19$ & 34 & 5 & 0.9 & 44 & -11 & -2.4 & $<0.05$ \\
\hline R 40 & 34 & -9 & -1.6 & 44 & -7 & -1.5 & ns \\
\hline \multicolumn{8}{|l|}{ Frontal Lobe } \\
\hline L lateral 8 & 34 & 9 & 1.6 & 44 & -6 & -1.2 & $=0.05$ \\
\hline L $8 / 9$ & 34 & 20 & 2.8 & 44 & -2 & -0.4 & $<0.05$ \\
\hline R 8/9 & 35 & 8 & 1.3 & 44 & -8 & -1.7 & $<0.05$ \\
\hline L 9 & 35 & 17 & 2.9 & 44 & -8 & -1.4 & $<0.005$ \\
\hline L 10 & 34 & 6 & 1.1 & 39 & -1 & -0.2 & ns \\
\hline 10 & 30 & -2 & -0.3 & 23 & -2 & -0.4 & ns \\
\hline L $10 / 47$ & 28 & 13 & 2.5 & 19 & -6 & -0.6 & $=0.051$ \\
\hline 32 & 20 & -10 & -1.0 & 15 & -18 & -1.7 & ns \\
\hline \multicolumn{8}{|l|}{ Temporal Lobe } \\
\hline L 20 & 20 & 18 & 2.7 & 12 & -10 & -0.8 & $<0.05$ \\
\hline $\mathrm{R}$ amygdala & 16 & -2 & -0.2 & 9 & -7 & -1.4 & ns \\
\hline
\end{tabular}

\section{Arousal}

Maquet et. al (1996) have measured PET activation during REM sleep, slow-wave sleep, and wakefulness. They report that REM sleep decreased blood flow, relative to the other states, in left and right parietal cortex, the precuneous and posterior cingulate, and several regions in dorsolateral prefrontal cortex. Since these foci were roughly 10 to $15 \mathrm{~mm}$ from the corresponding foci reported here, it is unclear if they represent the same areas. If REM sleep is an "active" state, while slow-wave sleep and wakefulness are low arousal states, a correspondence would suggest that decreases in these regions during the active tasks of the present report reflect changes in arousal. Maquet et al. also report, however, that REM sleep produced increases in the amygdala (9 $\mathrm{mm}$ from the present focus) and did not affect other foci from the present work, suggesting that an arousal interpretation may only account for a limited number of foci.

\section{Inbibition of Irrelevant Sensory Modalities}

Since all tasks involved visual stimuli, decreases may represent inhibition of task-irrelevant modalities such as somesthesis or audition (Haxby et al., 1994; Shulman, Corbetta, Buchner, Raichle, et al., 1997). Although none of the decreases occurred in primary sensory areas, some occurred in association cortex (e.g., the posterior insula, Table 2).

\section{Suppression of Habitual Response Systems}

Drevets and Raichle (in press) suggest that ventromedial frontal cortex and amygdala might show a reciprocal relationship with regions involved in cognitive processing. Based on evidence linking ventromedial frontal cortex to the generation and regulation of emotional states (Carmichael \& Price, 1995; Damasio, Tranel, \& Damasio, 1990; Drevets et al., 1992), they speculate that ventromedial areas are inhibited during difficult cognitive tasks. 


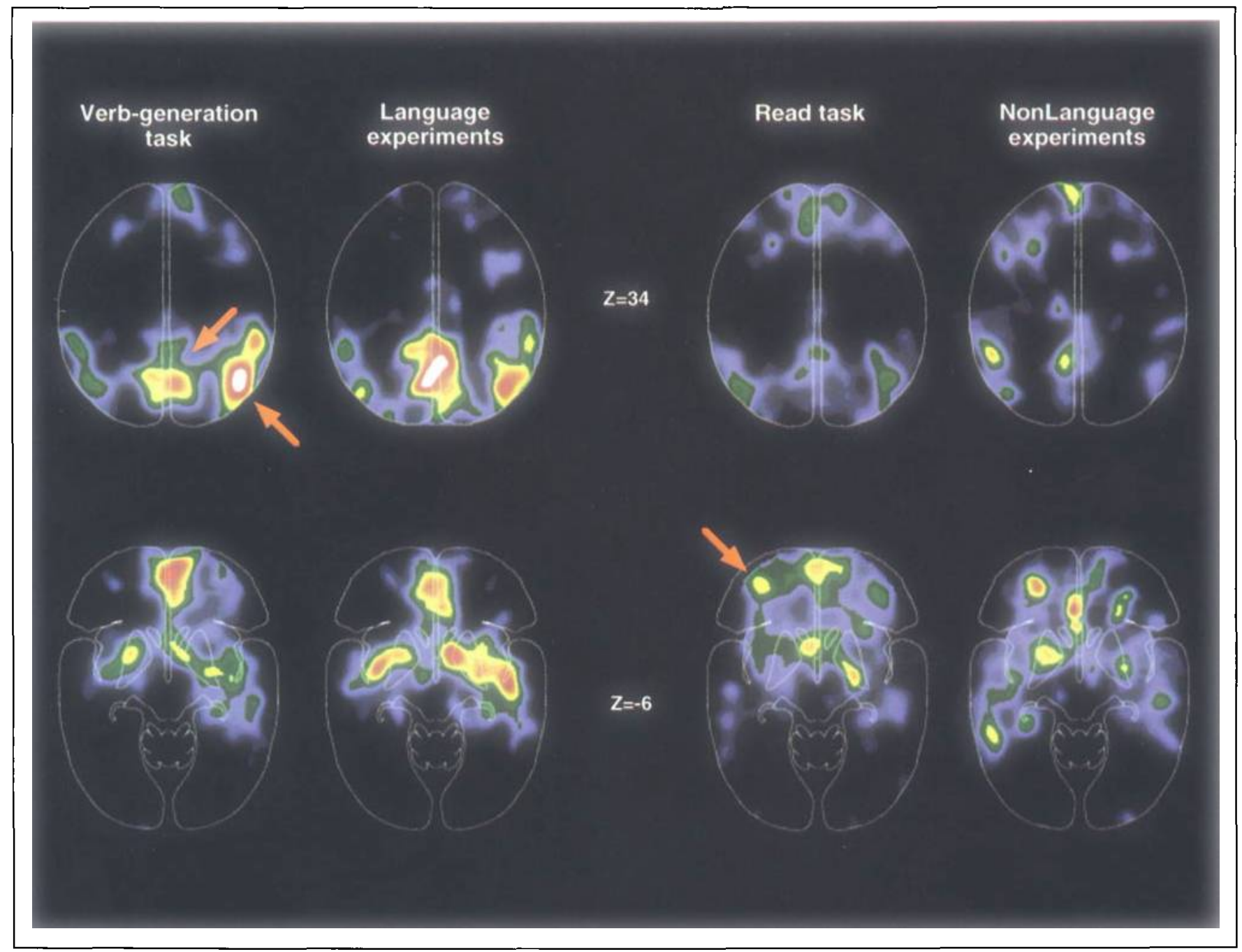

Figure 7. The left panel shows active minus passive decreases in the verb-generation conditions of the Practice Language and Language experiments and the active minus fixation decreases in the language megaimage combining data from the language-related studies. The right panel shows active minus passive decreases in the read conditions of the Practice language and Language experiments and the active minus fixation decreases in the nonlanguage megaimage combining data from the nonlanguage-related studies. This between-experiments comparison yields a very similar pattern of decreases to that seen in the verb-generation and read tasks. The color scale for the language and nonlanguage experiments was 0 (black) to -40 (white) PET counts, while the scale for the verb-generation and read tasks was 0 (black) to -60 (white) PET counts. Different scales were used because of the large differences in sample size.

Raichle et al. (1994) have contrasted two verbal response selection pathways, a sylvian/insular pathway that mediates relatively automatic or practiced behavior and a frontal/cingulate pathway that is active during unpracticed tasks requiring attentional involvement. Raichle suggests (personal communication, April 1997) that emotional arousal produces ventromedial frontal activity that favors the automatic pathway (e.g., under stress, the organism is biased toward habitual responses) and interferes with the performance of nonautomatic tasks. If nonautomatic tasks inhibit ventromedial areas to prevent this interference, decreases in ventromedial frontal cortex and the amygdala should be larger during the unpracticed verb-generation task than the read task. Decreases in these areas in the verb-generation task were slightly greater than in the read task, but the differences were not significant.

\section{Blood Flow Decreases Caused by Ongoing Processes in the Passive State}

\section{Unconstrained Verbal Thought Processes}

During the passive condition, subjects may think verbally about a variety of topics unrelated to the active tasks, producing left-hemisphere changes in superior and inferior frontal cortex and inferior temporal cortex. These regions showed larger decreases in the read than generate task and/or greater increases during the passive presentation of a letter string than a nonlanguage stimulus. Mazoyer et al. (1993) report that listening to prose passages increased blood flow in left inferior and superior frontal cortex, the middle temporal gyrus, and the temporal pole. Studies of single-word processing have also reported left frontal activity (Petersen, Fox, Posner, Mintun, \& Raichle, 1989; Price, Wise, \& Frackowiak, 1996). 
Although increases in left inferior temporal regions have not been consistently observed [temporal lobe increases are usually more posterior and/or superior (Fiez, Raichle, Balota, Tallal, \& Petersen, 1996), but see Price et al. (1996)], Bookheimer, Zeffiro, Blaxton, Gaillard, \& Theodore, (1995) report that silent, but not overt, word reading produced left inferior temporal increases. They also found increases in left inferior and superior frontal cortex.

\section{Monitoring of the External Environment}

During the passive condition, subjects may be in an "exploratory state," in which they monitor the external environment for novel or important events. Colby, Gattass, Olson, \& Gross (1988) report that area PO in the macaque parietal-occipital sulcus has a relatively greater representation of the peripheral visual field than most visual areas, and projects to a medial parietal area, MDP, which has cells with large receptive fields that habituate quickly. These properties of macaque PO/MDP may correspond to the decreases observed in the precuneous/posterior cingulate (BA 31/7). Decreases were most pronounced in experiments with foveal stimulation and were also marked in the corresponding passive minus fixation megaimages, which contained decreases in both the precuneous/cingulate and more posterior parietaloccipital regions. The fixation condition, in which the processing demands of the foveal stimulus were minor, may particularly free the subject to monitor the visual field for novel stimuli, producing large parietal-occipital changes.

\section{Monitoring of the Body Image}

During the passive condition, subjects may monitor the state of the body and its orientation in the external environment, constructing a sensory/perceptual representation of the self. These processes may reflect some of the parietal changes observed in the present analysis. Inferior parietal cortex is involved in many aspects of egocentric spatial processing (Andersen, 1987), and some regions are multimodal (Colby \& Duhamel, 1991). Right parietal lesions produce stronger neglect phenomenon than left parietal lesions, including disturbances of the body image and anosognosia. In the present work, both right and left inferior parietal regions showed larger decreases during the language than nonlanguage experiments, as well as larger decreases during the verb-generation than read task, but these effects appeared larger on the right side. Language-related tasks may have shifted attention to internal/symbolic representations and away from the body image/external environment more than the nonlanguage tasks, which required close attention to external stimuli.

\section{Monitoring of Emotional State}

It was noted above that ventromedial frontal cortex and amygdala may be inhibited during active tasks in order to prevent biases in cognitive processing produced by emotional arousal. These areas may also show increases in the passive condition from monitoring of the current emotional state, particularly the intermediate class of sensations ("background feelings") described by Damasio (1994) that corresponds to the body state between emotions.

Damasio (1994) has argued that ventromedial prefrontal regions can initiate emotional states associated through experience with particular contexts, by connections with the amygdala that produce body states appropriate to the emotion. He suggests that these body states are represented in primary (SI) and secondary (SII) somatosensory cortex and the insula. Active minus passive decreases were not found in primary somatosensory cortex (Shulman, Corbetta, Buckner, Fiez, et al.,1997), although decreases of moderate consistency were found bilaterally in the posterior insula (Table 2). Representations of body states may occur more posterior than primary somatosensory cortex in superior and inferior parietal areas (see above).

\section{Causes of Suspension of Passive Processes during Active Tasks}

Ongoing processes in the passive condition may be suspended during active tasks for several reasons. First, these processes may have an antithetical relationship to active task processes. Sleep, for example, is antithetical to an alert state. Similarly, a general exploratory/monitoring state may be antithetical to a task-focused state. Second, subjects may not "bother" to engage in passive processes when performing an active task, although they might engage these processes if this were necessary. Third, these processes may carry a cost and may be suspended during active tasks due to interference from high-to-low priority processes. Interference between tasks or processes may occur because they compete for the use of some general structure or resource that has a limited capacity (Posner, 1978), although interference also has "local" causes that depend on the task pairings being studied.

If suspension reflected competition between active and passive processes for a general structure or resource, the magnitude of the observed decreases should depend on the degree to which the active task involved those structures. More difficult tasks might use these structures to a greater degree, producing a greater suspension. There was little evidence, however, for an effect of task difficulty on decreases (see above). Similarly, asking subjects in the passive conditions to press a key each trial, which converted those conditions to simple detection tasks (see Note 3), did not produce passive minus fixa- 
tion decreases. Admittedly, these difficulty manipulations may have been too weak to show an effect. A threshold level of attentional involvement may be sufficient to dedicate the relevant neural regions to the active task.

The neural mechanisms of interference are unknown. The simplest idea is that interference between two tasks results when both tasks use the same set of neurons. If active and passive processes involved overlapping neural areas, interference would cause an active minus passive decrease in the nonoverlapping areas subserving the passive process and an active minus passive increase in the nonoverlapping areas subserving the active task process. Posner and Petersen (1990) have suggested that the anterior cingulate mediates an attentional function. If ongoing passive processes involved a network of areas that included the anterior cingulate, active visual tasks that heavily involved this region should have interfered more with these passive processes, producing larger decreases in noncingulate areas.

The data did not support this idea. Although the anterior cingulate did not yield consistent increases in the active minus passive megaimage, cingulate increases were found during individual tasks in particular experiments (e.g., divided attention). These tasks did not produce larger decreases than other tasks within the same experiment. Similarly, Visual Search 1 showed robust active minus passive anterior cingulate increases in all active conditions (Corbetta, Shulman, Miezin, Hunton, 8 Petersen, 1996) but did not show larger decreases relative to nonlanguage experiments that did not show a cingulate increase (e.g., Spatial Attention, Visual Search 2 and 3).

\section{METHOD}

The analysis stream from the previous paper (Shulman, Corbetta, Buckner, Raichle, et al., 1997) on blood flow increases was applied to the decreases. This stream involved analyses of (1) reliability, (2) between-experiments variation, (3) within-experiment variation, and (4) passive minus fixation data. The current paper also contains the analysis noted below.

\section{Active Minus Fixation Analyses}

Active minus fixation scans were analyzed to gain more information on baseline shifts induced by the presence of a stimulus in the passive condition. An active minus fixation megaimage was constructed from the seven experiments that included fixation scans, in which an impoverished visual stimulus (usually just a fixation cross) was presented and subjects were simply required to fixate. Seventy-six subjects contributed a total of 181 active minus fixation scan pairs. Although scans from a single subject were weighted to sum to one unit, equal weighting was not applied to the conditions within an experiment. There were many fewer active minus fixa- tion scans than active minus passive ones, making equal weighting of conditions inefficient.

\section{Acknowledgments}

We thank Tom Videen and Tom Yang for technical assistance. This work was supported by NIH grants NS06833, NS32979, EY08775, and HL13851; the Charles A. Dana Foundation; and the McDonnell Center for the Study of Higher Brain Function.

Reprint requests should be sent to Gordon Shulman, Department of Neurology, Box 8111, Washington University School of Medicine, $660 \mathrm{~S}$. Euclid, St. Louis, MO 63110 , or by e-mail to gordon@petcn.wustl.edu.

\section{Notes}

1. The magnitude criterion for the selection of foci from the generate megaimage was originally set at 15 PET counts for both increases and decreases. The criterion for the increases was lowered to $\mathbf{1 0}$ counts to guard against the possibility that the null results in cerebral cortex (see previous paper) resulted from too strict a criterion. If the decreases are also analyzed with a criterion of 10 counts, only one additional focus is included, in left dorsolateral prefrontal cortex (L BA 46; Table 2). 2. Roughly half of the scans in the language experiments were contributed by the Memory experiment. Buckner et al. (1995) noted that post-session interviews indicated that subjects acknowledged performing the stem completion task during the passive condition. It is possible that subjects also performed the active task to some degree in the passive conditions of other experiments. Covert performance of the active task during the passive condition will weaken the observed active minus passive decreases and should be reflected in passive minus fixation decreases at the megaimage foci. As noted later, the only decrease of this type that occurred to any significant extent was in the posterior cingulate/precuneous. Moreover, robust active minus passive decreases were found in the Memory experiment, suggesting that the passive condition in that experiment did differ from the active conditions.

3 . The term motor may be misleading. By requiring subjects to press a key on alternating trials, the passive condition was converted into a more active task in which subjects detected the presence of a stimulus and then pressed a key. The demands of this task state were apparently too small to produce blood flow decreases.

\section{REFERENCES}

Andersen, R. A. (1987). The role of the inferior parietal lobule in spatial perception and visual-motor integration. In F. Plum, V. B. Mountcastle, \& S. T. Geiger (Eds.), The bandbook of pbysiology. Section 1: The nervous system. Volume V.Higher functions of the brain part 2 (pp. 483518). Bethesda, MD: American Physiological Society.

Bookheimer, S. Y., Zeffiro, T. A., Blaxton, T., Gaillard, W., \& Theodore, W. (1995). Regional cerebral blood flow during object naming and word reading. Human Brain Mapping, 3, 93-106.

Broderson, P., Paulson, O. B., Bolwig, T. G., Rogon, E. Z., Rafaelsen, O. J., \& Lassen, N. A. (1973). Cerebral hyperemia in electrically induced epileptic seizures. Archives of Neurology, 28, 334-338.

Buckner, R. L., Petersen, S. E., Ojemann, J. G., Miezin, F. M., Squire, L. R., \& Raichle, M. E. (1995). Functional anatomi- 
cal studies of explicit and implicit memory retrieval tasks. Journal of Neuroscience, 15, 12-29.

Carmichael, S. T., \& Price, J. L. (1995). Limbic connections of the orbital and medial prefrontal cortex of macaque monkeys. Journal of Comparative Neurology, 368, 615641.

Colby, C. L., \& Duhamel, J. (1991). Heterogeneity of extrastriate visual areas and multiple parietal areas in the macaque monkey. Neuropswchologia. 29, 517-537.

Colby, C. L., Gattass, R., Olson, C. R., \& Gross, C. G. (1988). Topographic organization of cortical afferents to extrastriate visual area $P O$ in the macaque: $A$ dual tracer study. Journal of Comparative Neurology, 238, 1257-1299.

Corbetta, M., Shulman, G. L., Miezin, F. M., Hunton, D. L., \& Petersen, S. E. (1996). Frequency of targets in perceptual tasks does not modulate PET activity in the anterior cingulate cortex. Society for Neuroscience Abstracts, 22, 1855.

Damasio, A. R. (1994). Descartes' error. New York: Putnam.

Damasio, A. R., Tranel, D., \& Damasio, H. (1990). Individuals with sociopathic behavior caused by frontal damage fail to respond autonomically to social stimuli. Bebavioural Brain Research, 41, 81-94.

Drevets, W. C., \& Raichle, M. E. (in press). Reciprocal suppression of regional cerebral blood flow during emotional versus higher cognitive processes: Implication for interactions between emotion and cognition. Emotion and Cognition.

Drevets, W. C., Videen, T. O., Price, J. L., Preskorn, S. H., Carmichael, S. T., \& Raichle, M. E. (1992). A functional anatomical study of unipolar depression. Journal of Neuroscience, 12, 3628-3641.

Fiez, J. A., Raichle, M. E., Balota, D. A., Tallal, P., \& Petersen, S. E. (1996). PET activation of posterior temporal regions during passive auditory word presentation and verb generation. Cerebral Cortex, 6, 1-10.

Friston, K. J., Frith, C. D., Liddle, P. F, \& Frackowiak, R. S. J. (1991). Investigating a network model of word generation with positron emission tomography. Proceedings of the Royal Society of London-Series, B. Biological Sciences. 244, 101-106.

Haxby, J. V., Horwitz, B., Ungerleider, L. G., Maisog, J. M., Pietrini, P., \& Grady, C. L. (1994). The functional organization of human extrastriate cortex: A PET-rCBF study of selective attention to faces and locations. Journal of Neuroscience, 14, 6336-6353.
Hikosaka, O., \& Wurtz, R. H. (1983). Visual and oculomotor functions of monkey substantia nigra pars reticulata., I. Relation of visual and auditory responses to saccades. Journal of Neuropbysiology, 49, 1230-1253.

Maquet, P., Peters, J. M., Aerts, J., Delfiore, G., Degueldre, C., Luxen, A., \& Franck, G. (1996). Functional neuroanatomy of human rapid-eye-movement sleep and dreaming. $\mathrm{Na}$ ture, 383, 163-166.

Mazoyer, B. M., Dehaene, S., Tzouio, N., Frak, V., Murayama, N., Cohen, L., Levrier, O., Salamon, G., Syrota, A., \& Mehler, J. (1993). The cortical representation of speech.Journal of Cognitive Neuroscience, 5, 467-479.

Petersen, S. E., Fox, P. T., Posner, M. I., Mintun, M., \& Raichle, M. E. (1989). Positron emission tomographic studies of the processing of single words. Journal of Cognitive Neuroscience, 1, 153-170.

Plum, F, Posner, J. B., \& Troy, B. (1968). Cerebral metabolic and circulatory responses to induced convulsions in animals. Archives of Neurology, 18, 1-13.

Posner, J. B., Plum, F, \& Van Poznak, A. (1969). Cerebral metabolism during electrically induced seizures in man. Archives of Neurology, 20, 388-395.

Posner, M. I. (1978). Chronometric explorations of mind. Hillsdale: Erlbaum.

Posner, M. I., \& Petersen, S. E. (1990). The attention system of the human brain. Annual Review of Neuroscience, 13, 25-42.

Price, C. J., Wise, R. J. S., \& Frackowiak, R. S. J. (1996). Demonstrating the implicit processing of visually presented words and pseudowords. Cerebral Cortex. 6, 62-70.

Raichle, M. E., Fiez, J. A., Videen, T. O., MacLeod, A. K., Pardo, J. V., Fox, P. T., \& Petersen, S. E. (1994). Practice-related changes in human brain functional anatomy during nonmotor learning. Cerebral Cortex 4, 8-26.

Reivich, M. (1964). Arterial $\mathrm{PcO}_{2}$ and cerebral hemodynamics. American Journal of Physiology, 206, 25-35.

Shulman, G. L., Corbetta, M., Buckner, R. L., Fiez, J. A., Miezin, F. M., Raichle, M. E., \& Petersen, S. E. (1997). Common blood flow changes across visual tasks:, I. Increases in subcortical structures and cerebellum but not in nonvisual cortex. Journal of Cognitive Neuroscience, 9, 624-647.

Shulman, G. L., Corbetta, M., Buckner, R. L., Raichle, M. E., Fiez, J. A., Miezin, F. M., \& Petersen, S. E. (1997). Top-down modulation of early sensory cortex. Cerebral Cortex, 7, 193-206. 


\section{This article has been cited by:}

1. Reisa A. Sperling, Bradford C. Dickerson, Maija Pihlajamaki, Patrizia Vannini, Peter S. LaViolette, Ottavio V. Vitolo, Trey Hedden, J. Alex Becker, Dorene M. Rentz, Dennis J. Selkoe, Keith A. Johnson. 2010. Functional Alterations in Memory Networks in Early Alzheimer's Disease. NeuroMolecular Medicine . [CrossRef]

2. Dongyang Zhang, Marcus E. Raichle. 2010. Disease and the brain's dark energy. Nature Reviews Neurology 6:1, 15-28. [CrossRef]

3. George Bush. 2010. Attention-Deficit/Hyperactivity Disorder and Attention Networks. Neuropsychopharmacology 35:1, 278-300. [CrossRef]

4. J. R. Binder, R. H. Desai, W. W. Graves, L. L. Conant. 2010. Where Is the Semantic System? A Critical Review and Meta-Analysis of 120 Functional Neuroimaging Studies. Cerebral Cortex 19:12, 2767-2796. [CrossRef]

5. Denise DTDrfel, Annett Werner, Michael Schaefer, RDDdiger von Kummer, Anke Karl. 2009. Distinct brain networks in recognition memory share a defined region in the precuneus. European Journal of Neuroscience 30:10, 1947-1959. [CrossRef]

6. C. M. Lewis, A. Baldassarre, G. Committeri, G. L. Romani, M. Corbetta. 2009. From the Cover: Learning sculpts the spontaneous activity of the resting human brain. Proceedings of the National Academy of Sciences 106:41, 17558-17563. [CrossRef]

7. Lindsay Rutter, Frederick W. Carver, Tom Holroyd, Sreenivasan Rajamoni Nadar, Judy Mitchell-Francis, Jose Apud, Daniel R. Weinberger, Richard Coppola. 2009. Magnetoencephalographic gamma power reduction in patients with schizophrenia during resting condition. Human Brain Mapping 30:10, 3254-3264. [CrossRef]

8. Nan-kuei Chen, Ying-hui Chou, Allen W. Song, David J. Madden. 2009. Measurement of spontaneous signal fluctuations in fMRI: adult age differences in intrinsic functional connectivity. Brain Structure and Function 213:6, 571-585. [CrossRef]

9. Z. Shehzad, A. M. C. Kelly, P. T. Reiss, D. G. Gee, K. Gotimer, L. Q. Uddin, S. H. Lee, D. S. Margulies, A. K. Roy, B. B. Biswal, E. Petkova, F. X. Castellanos, M. P. Milham. 2009. The Resting Brain: Unconstrained yet Reliable. Cerebral Cortex 19:10, 2209-2229. [CrossRef]

10. C. L. Grady, A. B. Protzner, N. Kovacevic, S. C. Strother, B. Afshin-Pour, M. Wojtowicz, J. A. E. Anderson, N. Churchill, A. R. McIntosh. 2009. A Multivariate Analysis of Age-Related Differences in Default Mode and Task-Positive Networks across Multiple Cognitive Domains. Cerebral Cortex . [CrossRef]

11. Manuel Carreiras, Jordi Riba, Marta Vergara, Marcus Heldmann, Thomas F. Münte. 2009. Syllable congruency and word frequency effects on brain activation. Human Brain Mapping 30:9, 3079-3088. [CrossRef]

12. Mariët van Buuren, Thomas E. Gladwin, Bram B. Zandbelt, Martijn van den Heuvel, Nick F. Ramsey, René S. Kahn, Matthijs Vink. 2009. Cardiorespiratory effects on default-mode network activity as measured with fMRI. Human Brain Mapping 30:9, 3031-3042. [CrossRef]

13. Chiang-shan Ray Li, Sheng Zhang, Jeng-Ren Duann, Peisi Yan, Rajita Sinha, Carolyn M. Mazure. 2009. Gender Differences in Cognitive Control: an Extended Investigation of the Stop Signal Task. Brain Imaging and Behavior 3:3, 262-276. [CrossRef]

14. Elizabeth F. Chua, Daniel L. Schacter, Reisa A. Sperling. 2009. Neural Correlates of Metamemory: A Comparison of Feeling-of-Knowing and Retrospective Confidence JudgmentsNeural Correlates of Metamemory: A Comparison of Feeling-of-Knowing and Retrospective Confidence Judgments. Journal of Cognitive Neuroscience 21:9, 1751-1765. [Abstract] [Full Text] [PDF] [PDF Plus]

15. Michael C. Stevens, Godfrey D. Pearlson, Vince D. Calhoun. 2009. Changes in the interaction of resting-state neural networks from adolescence to adulthood. Human Brain Mapping 30:8, 2356-2366. [CrossRef]

16. Alexandre R. Franco, Aaron Pritchard, Vince D. Calhoun, Andrew R. Mayer. 2009. Interrater and intermethod reliability of default mode network selection. Human Brain Mapping 30:7, 2293-2303. [CrossRef]

17. Serge Chassagnon, Colin S. Hawko, Andrea Bernasconi, Jean Gotman, François Dubeau. 2009. Coexistence of symptomatic focal and absence seizures: Video-EEG and EEG-fMRI evidence of overlapping but independent epileptogenic networks. Epilepsia 50:7, 1821-1826. [CrossRef]

18. U. Hasson, H. C. Nusbaum, S. L. Small. 2009. Task-dependent organization of brain regions active during rest. Proceedings of the National Academy of Sciences 106:26, 10841-10846. [CrossRef]

19. G. Deco, V. Jirsa, A. R. McIntosh, O. Sporns, R. Kotter. 2009. Key role of coupling, delay, and noise in resting brain fluctuations. Proceedings of the National Academy of Sciences 106:25, 10302-10307. [CrossRef]

20. L. L. Beason-Held, M. A. Kraut, S. M. Resnick. 2009. Stability of Default-Mode Network Activity in the Aging Brain. Brain Imaging and Bebavior 3:2, 123-131. [CrossRef] 
21. K. Christoff, A. M. Gordon, J. Smallwood, R. Smith, J. W. Schooler. 2009. Experience sampling during fMRI reveals default network and executive system contributions to mind wandering. Proceedings of the National Academy of Sciences 106:21, 8719-8724. [CrossRef]

22. Karen Johanne Pallesen, Elvira Brattico, Christopher J. Bailey, Antti Korvenoja, Albert Gjedde. 2009. Cognitive and Emotional Modulation of Brain Default OperationCognitive and Emotional Modulation of Brain Default Operation. Journal of Cognitive Neuroscience 21:6, 1065-1080. [Abstract] [Full Text] [PDF] [PDF Plus]

23. Volker Diekmann, Reinhart Jürgens, Wolfgang Becker. 2009. Deriving angular displacement from optic flow: a fMRI study. Experimental Brain Research 195:1, 101-116. [CrossRef]

24. W. Gao, H. Zhu, K. S. Giovanello, J. K. Smith, D. Shen, J. H. Gilmore, W. Lin. 2009. Evidence on the emergence of the brain's default network from 2-week-old to 2-year-old healthy pediatric subjects. Proceedings of the National Academy of Sciences 106:16, 6790-6795. [CrossRef]

25. B. Y. Hayden, D. V. Smith, M. L. Platt. 2009. Electrophysiological correlates of default-mode processing in macaque posterior cingulate cortex. Proceedings of the National Academy of Sciences 106:14, 5948-5953. [CrossRef]

26. Janaina Mourao-Miranda, Christine Ecker, Joao R. Sato, Michael Brammer. 2009. Dynamic Changes in the Mental Rotation Network Revealed by Pattern Recognition Analysis of fMRI DataDynamic Changes in the Mental Rotation Network Revealed by Pattern Recognition Analysis of fMRI Data. Journal of Cognitive Neuroscience 21:5, 890-904. [Abstract] [Full Text] [PDF] [PDF Plus]

27. Jiliang Fang, Zhen Jin, Yin Wang, Ke Li, Jian Kong, Erika E. Nixon, Yawei Zeng, Yanshuang Ren, Haibin Tong, Yinghui Wang, Ping Wang, Kathleen Kin-Sang Hui. 2009. The salient characteristics of the central effects of acupuncture needling: Limbic-paralimbic-neocortical network modulation. Human Brain Mapping 30:4, 1196-1206. [CrossRef]

28. L. J. Larson-Prior, J. M. Zempel, T. S. Nolan, F. W. Prior, A. Z. Snyder, M. E. Raichle. 2009. Cortical network functional connectivity in the descent to sleep. Proceedings of the National Academy of Sciences 106:11, 4489-4494. [CrossRef]

29. 1. van oudenhove, j. vandenberghe, p. dupont, b. geeraerts, r. vos, g. bormans, k. van laere, b. fischler, k. demyttenaere, j. janssens, j. tack. 2009. Cortical deactivations during gastric fundus distension in health: visceral pain-specific response or attenuation of 'default mode' brain function? A H 215 O-PET study. Neurogastroenterology \& Motility 21:3, 259-271. [CrossRef]

30. Y. I. Sheline, D. M. Barch, J. L. Price, M. M. Rundle, S. N. Vaishnavi, A. Z. Snyder, M. A. Mintun, S. Wang, R. S. Coalson, M. E. Raichle. 2009. The default mode network and self-referential processes in depression. Proceedings of the National Academy of Sciences 106:6, 1942-1947. [CrossRef]

31. R. Nathan Spreng, Raymond A. Mar, Alice S. N. Kim. 2009. The Common Neural Basis of Autobiographical Memory, Prospection, Navigation, Theory of Mind, and the Default Mode: A Quantitative Meta-analysisThe Common Neural Basis of Autobiographical Memory, Prospection, Navigation, Theory of Mind, and the Default Mode: A Quantitative Meta-analysis. Journal of Cognitive Neuroscience 21:3, 489-510. [Abstract] [Full Text] [PDF] [PDF Plus]

32. Jed A. Meltzer, Greg A. Fonzo, R. Todd Constable. 2009. Transverse patterning dissociates human EEG theta power and hippocampal BOLD activation. Psychophysiology 46:1, 153-162. [CrossRef]

33. Maggie V. Mannell, Alexandre R. Franco, Vince D. Calhoun, Jose M. Cañive, Robert J. Thoma, Andrew R. Mayer. 2009. Resting state and task-induced deactivation: A methodological comparison in patients with schizophrenia and healthy controls. Human Brain Mapping NA-NA. [CrossRef]

34. Jonathan B. Freeman, Daniela Schiller, Nicholas O. Rule, Nalini Ambady. 2009. The neural origins of superficial and individuated judgments about ingroup and outgroup members. Human Brain Mapping NA-NA. [CrossRef]

35. Jutta S. Mayer, Alard Roebroeck, Konrad Maurer, David E.J. Linden. 2009. Specialization in the default mode: Task-induced brain deactivations dissociate between visual working memory and attention. Human Brain Mapping NA-NA. [CrossRef]

36. Annalisa Tosoni, Gaspare Galati, Gian Luca Romani, Maurizio Corbetta. 2009. Sensory-motor mechanisms in human parietal cortex underlie arbitrary visual decisions. Nature Neuroscience 11:12, 1446-1453. [CrossRef]

37. Vincent van de Ven, Christoph Bledowski, David Prvulovic, Rainer Goebel, Elia Formisano, Francesco Di Salle, David E.J. Linden, Fabrizio Esposito. 2009. Visual target modulation of functional connectivity networks revealed by self-organizing group ICA. Human Brain Mapping 29:12, 1450-1461. [CrossRef]

38. Donald J. Bolger, Jane Hornickel, Nadia E. Cone, Douglas D. Burman, James R. Booth. 2009. Neural correlates of orthographic and phonological consistency effects in children. Human Brain Mapping 29:12, 1416-1429. [CrossRef]

39. G. S. Wig, S. T. Grafton, K. E. Demos, G. L. Wolford, S. E. Petersen, W. M. Kelley. 2008. Medial temporal lobe BOLD activity at rest predicts individual differences in memory ability in healthy young adults. Proceedings of the National Academy of Sciences 105:47, 18555-18560. [CrossRef] 
40. Alan H. Lockwood, David S. Wack, Ralph H. B. Benedict, Mary Lou Coad, Joan E. Sussman, Robert F. Burkard. 2008. Multi-Site Phasic Neural Activity Mediates the Execution of An Auditory Continuous Performance Task: A PET and Electrophysiological Study. Journal of Neuroimaging 18:4, 364-374. [CrossRef]

41. Claire Calmels, Magaly Hars, Paul Holmes, Gilbert Jarry, Cornelis J. Stam. 2008. Non-linear EEG synchronization during observation and execution of simple and complex sequential finger movements. Experimental Brain Research 190:4, 389-400. [CrossRef]

42. Andreana P. Haley, John Gunstad, Ronald A. Cohen, Beth A. Jerskey, Richard C. Mulligan, Lawrence H. Sweet. 2008. Neural Correlates of Visuospatial Working Memory in Healthy Young Adults at Risk for Hypertension. Brain Imaging and Behavior 2:3, 192-199. [CrossRef]

43. B. J. Harrison, J. Pujol, M. Lopez-Sola, R. Hernandez-Ribas, J. Deus, H. Ortiz, C. Soriano-Mas, M. Yucel, C. Pantelis, N. Cardoner. 2008. Consistency and functional specialization in the default mode brain network. Proceedings of the National Academy of Sciences 105:28, 9781-9786. [CrossRef]

44. Michael D. Greicius, Vesa Kiviniemi, Osmo Tervonen, Vilho Vainionpää, Seppo Alahuhta, Allan L. Reiss, Vinod Menon. 2008. Persistent default-mode network connectivity during light sedation. Human Brain Mapping 29:7, 839-847. [CrossRef]

45. Melanie Boly, Christophe Phillips, Evelyne Balteau, Caroline Schnakers, Christian Degueldre, Gustave Moonen, Andre Luxen, Philippe Peigneux, Marie-Elisabeth Faymonville, Pierre Maquet, Steven Laureys. 2008. Consciousness and cerebral baseline activity fluctuations. Human Brain Mapping 29:7, 868-874. [CrossRef]

46. Alan H. Lockwood, David S. Wack, Ralph H. B. Benedict, Mary Lou Coad, Joan E. Sussman, Robert F. Burkard. 2008. Multi-Site Phasic Neural Activity Mediates the Execution of An Auditory Continuous Performance Task: A PET and Electrophysiological Study. Journal of Neuroimaging 18:3, 241-251. [CrossRef]

47. Simon D. Robinson, Jürgen Pripfl, Herbert Bauer, Ewald Moser. 2008. The impact of EPI voxel size on SNR and BOLD sensitivity in the anterior medio-temporal lobe: a comparative group study of deactivation of the Default Mode. Magnetic Resonance Materials in Physics, Biology and Medicine 21:4, 279-290. [CrossRef]

48. J.S. Anderson. 2008. Origin of Synchronized Low-Frequency Blood Oxygen Level-Dependent Fluctuations in the Primary Visual Cortex. American Journal of Neuroradiology 29:9, 1722-1729. [CrossRef]

49. Elizabeth A. Kensinger, Daniel L. Schacter. 2008. Neural Processes Supporting Young and Older Adults' Emotional MemoriesNeural Processes Supporting Young and Older Adults' Emotional Memories. Journal of Cognitive Neuroscience 20:7, 1161-1173. [Abstract] [PDF] [PDF Plus]

50. Silvina G. Horovitz, Masaki Fukunaga, Jacco A. de Zwart, Peter van Gelderen, Susan C. Fulton, Thomas J. Balkin, Jeff H. Duyn. 2008. Low frequency BOLD fluctuations during resting wakefulness and light sleep: A simultaneous EEG-fMRI study. Human Brain Mapping 29:6, 671-682. [CrossRef]

51. Ye Zhang, ShiGang Feng, HongBo Feng, Feng Dong, YiYuan Tang. 2008. The task dependent interaction of the deactivation regions. Chinese Science Bulletin 53:10, 1527-1532. [CrossRef]

52. A. D'Argembeau, D. Feyers, S. Majerus, F. Collette, M. Van der Linden, P. Maquet, E. Salmon. 2008. Self-reflection across time: cortical midline structures differentiate between present and past selves. Social Cognitive and Affective Neuroscience 3:3, 244-252. [CrossRef]

53. C. N. Boehler, T. F. Munte, R. M. Krebs, H. -J. Heinze, M. A. Schoenfeld, J. -M. Hopf. 2008. Sensory MEG Responses Predict Successful and Failed Inhibition in a Stop-Signal Task. Cerebral Cortex 19:1, 134-145. [CrossRef]

54. D. A. Fair, A. L. Cohen, N. U. F. Dosenbach, J. A. Church, F. M. Miezin, D. M. Barch, M. E. Raichle, S. E. Petersen, B. L. Schlaggar. 2008. The maturing architecture of the brain's default network. Proceedings of the National Academy of Sciences 105:10, 4028-4032. [CrossRef]

55. Marc Wermke, Christian Sorg, Afra M. Wohlschläger, Alexander Drzezga. 2008. A new integrative model of cerebral activation, deactivation and default mode function in Alzheimer's disease. European Journal of Nuclear Medicine and Molecular Imaging 35:S1, 12-24. [CrossRef]

56. S. L. Miller, K. Celone, K. DePeau, E. Diamond, B. C. Dickerson, D. Rentz, M. Pihlajamaki, R. A. Sperling. 2008. Age-related memory impairment associated with loss of parietal deactivation but preserved hippocampal activation. Proceedings of the National Academy of Sciences 105:6, 2181-2186. [CrossRef]

57. Jonathan Smallwood, Emily Beach, Jonathan W. Schooler, Todd C. Handy. 2008. Going AWOL in the Brain: Mind Wandering Reduces Cortical Analysis of External EventsGoing AWOL in the Brain: Mind Wandering Reduces Cortical Analysis of External Events. Journal of Cognitive Neuroscience 20:3, 458-469. [Abstract] [PDF] [PDF Plus] 
58. M. Boly, C. Phillips, L. Tshibanda, A. Vanhaudenhuyse, M. Schabus, T.T. Dang-Vu, G. Moonen, R. Hustinx, P. Maquet, S. Laureys. 2008. <i>Intrinsic Brain Activity in Altered States of Consciousness $<$ i $>$. Annals of the New York Academy of Sciences 1129:1, 119. [CrossRef]

59. Biyu J He, Gordon L Shulman, Abraham Z Snyder, Maurizio Corbetta. 2008. The role of impaired neuronal communication in neurological disorders. Current Opinion in Neurology 20:6, 655-660. [CrossRef]

60. J. A. Meltzer, H. P. Zaveri, I. I. Goncharova, M. M. Distasio, X. Papademetris, S. S. Spencer, D. D. Spencer, R. T. Constable. 2007. Effects of Working Memory Load on Oscillatory Power in Human Intracranial EEG. Cerebral Cortex 18:8, 1843-1855. [CrossRef]

61. Elizabeth F. Chua, Daniel L. Schacter, Erin Rand-Giovannetti, Reisa A. Sperling. 2007. Evidence for a specific role of the anterior hippocampal region in successful associative encoding. Hippocampus 17:11, 1071-1080. [CrossRef]

62. J. K. Rilling, S. K. Barks, L. A. Parr, T. M. Preuss, T. L. Faber, G. Pagnoni, J. D. Bremner, J. R. Votaw. 2007. A comparison of resting-state brain activity in humans and chimpanzees. Proceedings of the National Academy of Sciences 104:43, 17146-17151. [CrossRef]

63. Helmut Laufs, Khalid Hamandi, Afraim Salek-Haddadi, Andreas K. Kleinschmidt, John S. Duncan, Louis Lemieux. 2007. Temporal lobe interictal epileptic discharges affect cerebral activity in "default mode" brain regions. Human Brain Mapping 28:10, 1023-1032. [CrossRef]

64. Michael D. Fox, Marcus E. Raichle. 2007. Spontaneous fluctuations in brain activity observed with functional magnetic resonance imaging. Nature Reviews Neuroscience 8:9, 700-711. [CrossRef]

65. M. Boly, E. Balteau, C. Schnakers, C. Degueldre, G. Moonen, A. Luxen, C. Phillips, P. Peigneux, P. Maquet, S. Laureys. 2007. Baseline brain activity fluctuations predict somatosensory perception in humans. Proceedings of the National Academy of Sciences 104:29, 12187-12192. [CrossRef]

66. HongBo Feng, Ye Zhang, YiYuan Tang, Jing Jin, Feng Dong, ShiGang Feng, WuTian Zhang. 2007. Deactivations during the numerical processing. Chinese Science Bulletin 52:13, 1807-1812. [CrossRef]

67. J. L. Vincent, G. H. Patel, M. D. Fox, A. Z. Snyder, J. T. Baker, D. C. Van Essen, J. M. Zempel, L. H. Snyder, M. Corbetta, M. E. Raichle. 2007. Intrinsic functional architecture in the anaesthetized monkey brain. Nature 447:7140, 83-86. [CrossRef]

68. Jonas Persson, Cindy Lustig, James K. Nelson, Patricia A. Reuter-Lorenz. 2007. Age Differences in Deactivation: A Link to Cognitive Control?Age Differences in Deactivation: A Link to Cognitive Control?. Journal of Cognitive Neuroscience 19:6, 1021-1032. [Abstract] [PDF] [PDF Plus]

69. Arnaud D'Argembeau, Perrine Ruby, Fabienne Collette, Christian Degueldre, Evelyne Balteau, André Luxen, Pierre Maquet, Eric Salmon. 2007. Distinct Regions of the Medial Prefrontal Cortex Are Associated with Self-referential Processing and Perspective TakingDistinct Regions of the Medial Prefrontal Cortex Are Associated with Self-referential Processing and Perspective Taking. Journal of Cognitive Neuroscience 19:6, 935-944. [Abstract] [PDF] [PDF Plus]

70. J.M. Jansma, N.F. Ramsey, J.A. de Zwart, P. van Gelderen, J.H. Duyn. 2007. fMRI study of effort and information processing in a working memory task. Human Brain Mapping 28:5, 431-440. [CrossRef]

71. Aaron L Mishara. 2007. Missing links in phenomenological clinical neuroscience: why we still are not there yet. Current Opinion in Psycbiatry 20:6, 559. [CrossRef]

72. Turhan Canli, Klaus-Peter Lesch. 2007. Long story short: the serotonin transporter in emotion regulation and social cognition. Nature Neuroscience 10:9, 1103. [CrossRef]

73. Rachel Marsh, Hongtu Zhu, Robert T. Schultz, Georgette Quackenbush, Jason Royal, Pawel Skudlarski, Bradley S. Peterson. 2006. A developmental fMRI study of self-regulatory control. Human Brain Mapping 27:11, 848-863. [CrossRef]

74. Vladimir L. Cherkassky, Rajesh K. Kana, Timothy A. Keller, Marcel Adam Just. 2006. Functional connectivity in a baseline resting-state network in autism. NeuroReport 17:16, 1687-1690. [CrossRef]

75. J. S. Damoiseaux, S. A. R. B. Rombouts, F. Barkhof, P. Scheltens, C. J. Stam, S. M. Smith, C. F. Beckmann. 2006. Consistent resting-state networks across healthy subjects. Proceedings of the National Academy of Sciences 103:37, 13848-13853. [CrossRef]

76. J. M. Moran, C. N. Macrae, T. F. Heatherton, C. L. Wyland, W. M. Kelley. 2006. Neuroanatomical Evidence for Distinct Cognitive and Affective Components of SelfNeuroanatomical Evidence for Distinct Cognitive and Affective Components of Self. Journal of Cognitive Neuroscience 18:9, 1586-1594. [Abstract] [PDF] [PDF Plus]

77. Marcus E. Raichle, Mark A. Mintun. 2006. BRAIN WORK AND BRAIN IMAGING. Annual Review of Neuroscience 29:1, 449-476. [CrossRef] 
78. Christina Scheibe, Isabell Wartenburger, Torsten Wüstenberg, Norbert Kathmann, Arno Villringer, Hauke R. Heekeren. 2006. Neural correlates of the interaction between transient and sustained processes: A mixed blocked/event-related fMRI study. Human Brain Mapping 27:7, 545-551. [CrossRef]

79. Amir Shmuel, Mark Augath, Axel Oeltermann, Nikos K Logothetis. 2006. Negative functional MRI response correlates with decreases in neuronal activity in monkey visual area V1. Nature Neuroscience 9:4, 569-577. [CrossRef]

80. Claire Calmels, Paul Holmes, Gilbert Jarry, Magaly Hars, Emilie Lopez, Aurore Paillard, Cornelis J. Stam. 2006. Variability of EEG synchronization prior to and during observation and execution of a sequential finger movement. Human Brain Mapping 27:3, 251-266. [CrossRef]

81. Anthony B. Waites, Regula S. Briellmann, Michael M. Saling, David F. Abbott, Graeme D. Jackson. 2006. Functional connectivity networks are disrupted in left temporal lobe epilepsy. Annals of Neurology 59:2, 335-343. [CrossRef]

82. Cheryl L. Grady, Mellanie V. Springer, Donaya Hongwanishkul, Anthony R. McIntosh, Gordon Winocur. 2006. Age-related Changes in Brain Activity across the Adult LifespanAge-related Changes in Brain Activity across the Adult Lifespan. Journal of Cognitive Neuroscience 18:2, 227-241. [Abstract] [PDF] [PDF Plus]

83. Kazuo Hiraki, Naoko Dan, Goh Matsuda. 2006. The Journal of The Institute of Image Information and Television Engineers 60:11, 1745-1748. [CrossRef]

84. Marcus E. Raichle, Debra A. Gusnard. 2006. Intrinsic brain activity sets the stage for expression of motivated behavior. The Journal of Comparative Neurology 493:1, 167-176. [CrossRef]

85. Serge A.R.B. Rombouts, Frederik Barkhof, Rutger Goekoop, Cornelis J. Stam, Philip Scheltens. 2006. Altered resting state networks in mild cognitive impairment and mild Alzheimer's disease: An fMRI study. Human Brain Mapping 26:4, 231-239. [CrossRef]

86. Peter Fransson. 2005. Spontaneous low-frequency BOLD signal fluctuations: An fMRI investigation of the resting-state default mode of brain function hypothesis. Human Brain Mapping 26:1, 15-29. [CrossRef]

87. Jason P. Mitchell , Mahzarin R. Banaji , C. Neil Macrae . 2005. The Link between Social Cognition and Self-referential Thought in the Medial Prefrontal CortexThe Link between Social Cognition and Self-referential Thought in the Medial Prefrontal Cortex. Journal of Cognitive Neuroscience 17:8, 1306-1315. [Abstract] [PDF] [PDF Plus]

88. Motoaki Sugiura, Nadim J. Shah, Karl Zilles, Gereon R. Fink. 2005. Cortical Representations of Personally Familiar Objects and Places: Functional Organization of the Human Posterior Cingulate CortexCortical Representations of Personally Familiar Objects and Places: Functional Organization of the Human Posterior Cingulate Cortex. Journal of Cognitive Neuroscience 17:2, 183-198. [Abstract] [PDF] [PDF Plus]

89. Anthony B. Waites, Alexandra Stanislavsky, David F. Abbott, Graeme D. Jackson. 2005. Effect of prior cognitive state on resting state networks measured with functional connectivity. Human Brain Mapping 24:1, 59-68. [CrossRef]

90. J. Richard Jennings, Maurits W. van der Molen. 2005. Preparation for Speeded Action as a Psychophysiological Concept. Psychological Bulletin 131:3, 434-459. [CrossRef]

91. Michael D. Greicius, Vinod Menon. 2004. Default-Mode Activity during a Passive Sensory Task: Uncoupled from Deactivation but Impacting ActivationDefault-Mode Activity during a Passive Sensory Task: Uncoupled from Deactivation but Impacting Activation. Journal of Cognitive Neuroscience 16:9, 1484-1492. [Abstract] [PDF] [PDF Plus]

92. K. Vogeley , M. May , A. Ritzl , P. Falkai , K. Zilles , G. R. Fink . 2004. Neural Correlates of First-Person Perspective as One Constituent of Human Self-ConsciousnessNeural Correlates of First-Person Perspective as One Constituent of Human Self-Consciousness. Journal of Cognitive Neuroscience 16:5, 817-827. [Abstract] [PDF] [PDF Plus]

93. Howard J. Aizenstein, Kristi A. Clark, Meryl A. Butters, Jennifer Cochran , V. Andrew Stenger , Carolyn C. Meltzer, Charles F. Reynolds , Cameron S. Carter . 2004. The BOLD Hemodynamic Response in Healthy AgingThe BOLD Hemodynamic Response in Healthy Aging. Journal of Cognitive Neuroscience 16:5, 786-793. [Abstract] [PDF] [PDF Plus]

94. Robert L. Hester, Kevin Murphy, John J. Foxe, Deirdre M. Foxe, Daniel C. Javitt, Hugh Garavan . 2004. Predicting Success: Patterns of Cortical Activation and Deactivation Prior to Response InhibitionPredicting Success: Patterns of Cortical Activation and Deactivation Prior to Response Inhibition. Journal of Cognitive Neuroscience 16:5, 776-785. [Abstract] [PDF] [PDF Plus]

95. Andrew T. Smith, Adrian L. Williams, Krishna D. Singh. 2004. Negative BOLD in the visual cortex: Evidence against blood stealing. Human Brain Mapping 21:4, 213-220. [CrossRef]

96. Catherine L. Reed, Shy Shoham, Eric Halgren. 2004. Neural substrates of tactile object recognition: An fMRI study. Human Brain Mapping 21:4, 236-246. [CrossRef]

97. Sridhar S. Kannurpatti, Bharat B. Biswal. 2004. Negative Functional Response to Sensory Stimulation and Its Origins. Journal of Cerebral Blood Flow \&\#38 Metabolism 703. [CrossRef] 
98. Andrew P. Bagshaw, Yahya Aghakhani, Christian-G. Bénar, Eliane Kobayashi, Colin Hawco, François Dubeau, G. Bruce Pike, Jean Gotman. 2004. EEG-fMRI of focal epileptic spikes: Analysis with multiple haemodynamic functions and comparison with gadolinium-enhanced MR angiograms. Human Brain Mapping 22:3, 179. [CrossRef]

99. Yuhong Jiang, Nancy Kanwisher. 2003. Common Neural Mechanisms for Response Selection and Perceptual ProcessingCommon Neural Mechanisms for Response Selection and Perceptual Processing. Journal of Cognitive Neuroscience 15:8, 1095-1110. [Abstract] [PDF] [PDF Plus]

100. Jesse Rissman, James C. Eliassen, Sheila E. Blumstein. 2003. An Event-Related fMRI Investigation of Implicit Semantic PrimingAn Event-Related fMRI Investigation of Implicit Semantic Priming. Journal of Cognitive Neuroscience 15:8, 1160-1175. [Abstract] [PDF] [PDF Plus]

101. Yuhong Jiang, Nancy Kanwisher. 2003. Common Neural Substrates for Response Selection across Modalities and Mapping ParadigmsCommon Neural Substrates for Response Selection across Modalities and Mapping Paradigms. Journal of Cognitive Neuroscience 15:8, 1080-1094. [Abstract] [PDF] [PDF Plus]

102. Jeffrey M. Zacks, Jean M. Vettel, Pascale Michelon. 2003. Imagined Viewer and Object Rotations Dissociated with Event-Related fMRIImagined Viewer and Object Rotations Dissociated with Event-Related fMRI. Journal of Cognitive Neuroscience 15:7, 1002-1018. [Abstract] [PDF] [PDF Plus]

103. Natalia S. Lawrence, Thomas J. Ross, Ray Hoffmann, Hugh Garavan, Elliot A. Stein. 2003. Multiple Neuronal Networks Mediate Sustained AttentionMultiple Neuronal Networks Mediate Sustained Attention. Journal of Cognitive Neuroscience 15:7, 1028-1038. [Abstract] [PDF] [PDF Plus]

104. Thierry Chaminade, Pierre Fonlupt. 2003. Changes of effective connectivity between the lateral and medial parts of the prefrontal cortex during a visual task. European Journal of Neuroscience 18:3, 675-679. [CrossRef]

105. J. R. Binder, K. A. McKiernan, M. E. Parsons, C. F. Westbury, E. T. Possing, J. N. Kaufman, L. Buchanan. 2003. Neural Correlates of Lexical Access during Visual Word RecognitionNeural Correlates of Lexical Access during Visual Word Recognition. Journal of Cognitive Neuroscience 15:3, 372-393. [Abstract] [PDF] [PDF Plus]

106. Kristen A. McKiernan, Jacqueline N. Kaufman, Jane Kucera-Thompson, Jeffrey R. Binder. 2003. A Parametric Manipulation of Factors Affecting Task-induced Deactivation in Functional NeuroimagingA Parametric Manipulation of Factors Affecting Task-induced Deactivation in Functional Neuroimaging. Journal of Cognitive Neuroscience 15:3, 394-408. [Abstract] [PDF] [PDF Plus]

107. Andrea Mechelli , Maria Luisa Gorno-Tempini , Cathy J. Price . 2003. Neuroimaging Studies of Word and Pseudoword Reading: Consistencies, Inconsistencies, and LimitationsNeuroimaging Studies of Word and Pseudoword Reading: Consistencies, Inconsistencies, and Limitations. Journal of Cognitive Neuroscience 15:2, 260-271. [Abstract] [PDF] [PDF Plus]

108. Gina R. Kuperberg, Phillip J. Holcomb , Tatiana Sitnikova, Douglas Greve, Anders M. Dale, David Caplan . 2003. Distinct Patterns of Neural Modulation during the Processing of Conceptual and Syntactic AnomaliesDistinct Patterns of Neural Modulation during the Processing of Conceptual and Syntactic Anomalies. Journal of Cognitive Neuroscience 15:2, 272-293. [Abstract] [PDF] [PDF Plus]

109. W. M. Kelley, C. N. Macrae , C. L. Wyland, S. Caglar , S. Inati , T. F. Heatherton . 2002. Finding the Self? An Event-Related fMRI StudyFinding the Self? An Event-Related fMRI Study. Journal of Cognitive Neuroscience 14:5, 785-794. [Abstract] [PDF] [PDF Plus]

110. Murray Grossman, Phyllis Koenig, Chris DeVita, Guila Glosser, David Alsop, John Detre, James Gee. 2002. Neural representation of verb meaning: An fMRI study. Human Brain Mapping 15:2, 124-134. [CrossRef]

111. Leanne Tamm, Vinod Menon, Cindy K. Johnston, David R. Hessl, Allan L. Reiss . 2002. fMRI Study of Cognitive Interference Processing in Females with Fragile X SyndromefMRI Study of Cognitive Interference Processing in Females with Fragile X Syndrome. Journal of Cognitive Neuroscience 14:2, 160-171. [Abstract] [PDF] [PDF Plus]

112. Michele Ferrara, Luigi De Gennaro, Giuseppe Curcio, Riccardo Cristiani, Mario Bertini. 2002. Interhemispheric asymmetry of human sleep EEG in response to selective slow-wave sleep deprivation. Behavioral Neuroscience 116:6, 976-981. [CrossRef]

113. Noam Harel, Sang-Pil Lee, Tsukasa Nagaoka, Dae-Shik Kim, Seong-Gi Kim. 2002. Origin of Negative Blood Oxygenation Level???Dependent fMRI Signals. Journal of Cerebral Blood Flow \&\#38 Metabolism 908. [CrossRef]

114. Debra A. Gusnard, Marcus E. Raichle. 2001. Searching for a baseline: Functional imaging and the resting human brain. Nature Reviews Neuroscience 2:10, 685-694. [CrossRef]

115. Scott A. Huettel, Güven Güzeldere, Gregory McCarthy. 2001. Dissociating the Neural Mechanisms of Visual Attention in Change Detection Using Functional MRIDissociating the Neural Mechanisms of Visual Attention in Change Detection Using Functional MRI. Journal of Cognitive Neuroscience 13:7, 1006-1018. [Abstract] [PDF] [PDF Plus] 
116. Ziad S. Saad, Kristina M. Ropella, Robert W. Cox, Edgar A. DeYoe. 2001. Analysis and use of FMRI response delays. Human Brain Mapping 13:2, 74. [CrossRef]

117. Todd C. Handy. 2000. Capacity Theory as a Model of Cortical BehaviorCapacity Theory as a Model of Cortical Behavior. Journal of Cognitive Neuroscience 12:6, 1066-1069. [Abstract] [PDF] [PDF Plus]

118. Joseph R. Simpson, Dost Öngür, Erbil Akbudak, Thomas E. Conturo, John M. Ollinger, Abraham Z. Snyder, Debra A. Gusnard, Marcus E. Raichle . 2000. The Emotional Modulation of Cognitive Processing: An fMRI StudyThe Emotional Modulation of Cognitive Processing: An fMRI Study. Journal of Cognitive Neuroscience 12:supplement 2, 157-170. [Abstract] [PDF] [PDF Plus]

119. S. Pollmann, R. Weidner , H.J. Müller , D.Y. von Cramon . 2000. A Fronto-Posterior Network Involved in Visual Dimension ChangesA Fronto-Posterior Network Involved in Visual Dimension Changes. Journal of Cognitive Neuroscience 12:3, 480-494. [Abstract] [PDF] [PDF Plus]

120. Kathleen K.S. Hui, Jing Liu, Nikos Makris, Randy L. Gollub, Anthony J.W. Chen, Christopher I. Moore, David N. Kennedy, Bruce R. Rosen, Kenneth K. Kwong. 2000. Acupuncture modulates the limbic system and subcortical gray structures of the human brain: Evidence from fMRI studies in normal subjects. Human Brain Mapping 9:1, 13-25. [CrossRef]

121. Rajendra D. Badgaiyan, Daniel L. Schacter, Nathaniel M. Alpert . 1999. Auditory Priming within and across Modalities: Evidence from Positron Emission TomographyAuditory Priming within and across Modalities: Evidence from Positron Emission Tomography. Journal of Cognitive Neuroscience 11:4, 337-348. [Abstract] [PDF] [PDF Plus]

122. Allyson C. Rosen, Stephen M. Rao, Paolo Caffarra, Augusto Scaglioni, Julie A. Bobholz, Scott J. Woodley, Thomas A. Hammeke, Joseph M. Cunningham, Thomas E. Prieto , Jeffrey R. Binder . 1999. Neural Basis of Endogenous and Exogenous Spatial Orienting: A Functional MRI StudyNeural Basis of Endogenous and Exogenous Spatial Orienting: A Functional MRI Study. Journal of Cognitive Neuroscience 11:2, 135-152. [Abstract] [PDF] [PDF Plus]

123. K. Sathian, Tony J. Simon, Scott Peterson, Gargi A. Patel, John M. Hoffman, Scott T. Grafton. 1999. Neural Evidence Linking Visual Object Enumeration and AttentionNeural Evidence Linking Visual Object Enumeration and Attention. Journal of Cognitive Neuroscience 11:1, 36-51. [Abstract] [PDF] [PDF Plus]

124. J. R. Binder, J. A. Frost, T. A. Hammeke, P. S. F. Bellgowan, S. M. Rao, R. W. Cox. 1999. Conceptual Processing during the Conscious Resting State: A Functional MRI StudyConceptual Processing during the Conscious Resting State: A Functional MRI Study. Journal of Cognitive Neuroscience 11:1, 80-93. [Abstract] [PDF] [PDF Plus]

125. Jeffrey G. Ojemann, Randy L. Buckner, Erbil Akbudak, Abraham Z. Snyder, John M. Ollinger, Robert C. Mckinstry, Bruce R. Rosen, Steve E. Petersen, Marcus E. Raichle, Thomas E. Conturo. 1998. Functional MRI studies of word-stem completion: Reliability across laboratories and comparison to blood flow imaging with PET. Human Brain Mapping 6:4, 203-215. [CrossRef]

126. Denise C. Park, Joshua GohSuccessful Aging . [CrossRef] 